\title{
Effect of Upper Mantle Density Structure on Moho Geometry
}

\author{
Robert Tenzer, ${ }^{1}$ Wenjin Chen, ${ }^{1}$ and ShuangGen $\mathrm{JiN}^{2}$
}

\begin{abstract}
A constant value of the Moho density contrast is often assumed in the gravimetric methods used for determination of Moho geometry. This assumption might be sufficient in regional studies with a relatively homogenous lithospheric structure (and, consequently, small lateral variations in Moho density contrast). In global studies, however, this assumption is not reasonable, because not only the Moho depth but also the Moho density contrast vary substantially, and are, thus, likely to result in systematic errors in Moho geometry determined globally from gravity data. In this study we address this issue by investigating the effect of variable Moho density contrast on Moho geometry. We demonstrate that assumption of variable Moho density contrast (instead of a uniform model) substantially improves agreement between the global gravimetric and seismic Moho models by approximately $30 \%$.
\end{abstract}

Key words: Crust, density contrast, gravity, upper mantle, Moho interface.

\section{Introduction}

In gravimetric methods for global recovery of Moho depths a uniform density contrast at the Moho interface is often assumed (MORITZ 1990; С̆ $\mathrm{ADEK}$ and Martinec 1991; Brattenberg and Zadro 1999; BraITENBERG et al. 2006, 2010; WIENECKE et al. 2007, SJÖBERG 2009; SAMPIETRo 2011; Bagherbandi and SJöBerg, 2012; SAmpietro et al. 2013; Tenzer and Chen 2014a, b). An average value of the Moho density contrast of $600 \mathrm{~kg} \mathrm{~m}^{-3}$ is typically adopted (Heiskanen and Moritz 1967, p. 135). Several authors have given different estimates. DzIEwonski and ANDERson (1981), for instance, adopted the value

1 The Key Laboratory of Geospace Environment and Geodesy, School of Geodesy and Geomatics, Chinese Ministry of Education, Wuhan University, 129 Luoyu Road, Wuhan 430079, China. E-mail: rtenzer@sgg.whu.edu.cn

2 Chinese Academy of Sciences, Shanghai Astronomical Observatory, 80 Nandan Road, Shanghai 200030, China. of $480 \mathrm{~kg} \mathrm{~m}^{-3}$ for the global crust-mantle density contrast in the definition of the preliminary reference earth model (PREM). This value was derived from analysis of available global seismic data. Tenzer et al. (2009a) estimated the average value of the Moho density contrast by minimizing a global spatial correlation between gravity data and Moho depths taken from the CRUST2.0 seismic crustal model (BASsin et al. 2000). According to their result, the average value was found to be $520 \mathrm{~kg} \mathrm{~m}^{-3}$. Later, Tenzer et al. (2012c) and Tenzer and Bagherbandi (2013) updated this value to 485 and $441 \mathrm{~kg} \mathrm{~m}^{-3}$, respectively, on the basis of more recent datasets and more accurate numerical models. SJöBERG and BAGHERBANDI (2011) estimated the global average of the Moho density contrast of $448 \pm 187 \mathrm{~kg} \mathrm{~m}^{-3}$ by solving the Vening Meinesz-Moritz (VMM) inverse problem of isostasy (Vening Meinesz 1931; HeIsKANEn and Vening Meinesz 1958; Moritz 1990; SJöberg 2009, 2013).

Results from seismic and gravimetric studies revealed that the Moho density contrast varies substantially (Geiss 1987; MartineC 1994; KabAn et al. 2003; SJÖBERg and BAgherbandi 2011; TEnZER et al. 2012d; Tenzer and Bagherbandi 2013). Goodacre (1972), for instance, reported a continental Moho density contrast of $200 \mathrm{~kg} \mathrm{~m}^{3}$ in Canada. MartineC (1994) claimed that a value of $600 \mathrm{~kg} \mathrm{~m}^{-3}$ agrees better with the Moho density contrast under the oceanic crust. He also estimated an average value of $280 \mathrm{~kg} \mathrm{~m}^{-3}$ for the continental crust by minimizing the external gravitational potential induced by the Earth's topographic masses and the Moho discontinuity under the assumption that the Moho density contrast is constant. NIU and JAMES (2002) and JORDI (2007) determined the Moho density contrast regionally from seismic data using the wave receiver functions. Their results showed that the density 
contrast varies regionally from $160 \mathrm{~kg} \mathrm{~m}^{3}$ (for the mafic lower crust) to $440 \mathrm{~kg} \mathrm{~m}^{-3}$ (for the felsic lower crust), with an apparently typical value for the craton of approximately $440 \mathrm{~kg} \mathrm{~m}^{-3}$. ARTEMIEVA (2007) demonstrated that the in-situ density contrast between the crystalline crust and the lithospheric upper mantle differs substantially between the Cratonic and the Phanerozoic crust: approximately $500 \mathrm{~kg} \mathrm{~m}^{-3}$ for the crust beneath Western Europe, between 300 and $350 \mathrm{~kg} \mathrm{~m}^{-3}$ for most of the Precambrian crust, and by as little as $150-250 \mathrm{~kg} \mathrm{~m}^{-3}$ for some parts of the Baltic and the Ukrainian shields.

Much large values of the Moho density contrast were estimated from gravimetric studies, especially under orogens with density contrast locally exceeding even $900 \mathrm{~kg} \mathrm{~m}^{-3}$. Such high density contrasts are, however, not compatible with petro-physical models. SJöBERG and BAGHERBANDi (2011), for instance, estimated that the Moho density contrast varies globally from $81.5 \mathrm{~kg} \mathrm{~m}^{-3}$ (in the Pacific region) to $988 \mathrm{~kg} \mathrm{~m}^{-3}$ (beneath the Tibetan Plateau). They also provided the average values of $678 \pm 78$ and $334 \pm 108 \mathrm{~kg} \mathrm{~m}^{-3}$ for the continental and oceanic areas, respectively. TENZER et al. (2012d) reported a similar range of Moho density contrast (taken relative to the reference crustal density of $2,670 \mathrm{~kg} \mathrm{~m}^{-3}$ ) of between 82 and $965 \mathrm{~kg} \mathrm{~m}^{-3}$. They also demonstrated that the Moho density contrast under the oceanic crust is highly spatially correlated with the age of the oceanic lithosphere; the density contrast minima are located along the oceanic rift zones and the corresponding maxima are along the oceanic subduction zones. Tenzer and BAgherbandi (2013) investigated the structure of the crust-mantle density interface beneath Antarctica. They found large values of Moho density contrast throughout the central part of East Antarctica with the extension under the Transantarctic mountain range, with values there typically exceeding $500 \mathrm{~kg} \mathrm{~m}^{-3}$ and maxima up to $682 \mathrm{~kg} \mathrm{~m}^{-3}$. In West Antarctica the density contrast is typically $400-500 \mathrm{~kg} \mathrm{~m}^{-3}$ (except for local maxima up to approx. $550 \mathrm{~kg} \mathrm{~m}^{-3}$ in the central part of the Antarctic Peninsula). They also explained the local minima (400-450 $\mathrm{kg} \mathrm{m}^{-3}$ ) beneath the WestAntarctic rift zone and Ross Embayment on the basis of the volcanic composition along this divergent tectonic zone.
Large density contrast variations at the Moho interface indicate that assumption of a uniform model might not be sufficient for accurate determination of Moho geometry from gravity data, especially in global studies and in regions with a complex lithospheric structure and, consequently, large Moho density contrast variations. Moreover, geodynamic processes may regionally alter the crustal composition. In areas with large magmatic production, for instance, the lower crust may be affected by under-plating, as found beneath large igneous provinces in the Parana and West Siberian basins and in the Deccan Traps (cf. Braitenberg and EbBing 2009; Mariani et al. 2013; Thyвo and Artemieva 2013). Furthermore, in orogenic roots high-pressure metamorphism may place highly densified rocks at a lower crustal level.

A possible method of dealing with this problem was proposed by SJöBERG and BAGHERBANDI (2011). They developed and applied a least-squares approach which combined seismic and gravity data in the VMM isostatic inverse scheme for simultaneous estimation of the Moho depth and density contrast. In this study, we propose an alternative method, which incorporates the variable Moho density contrast as the a-priori information in gravimetric determination of the Moho depth. For this purpose, we reformulate the expressions for the gravimetric forward and inverse modeling given by TENZER and CHen (2014a). Their method assumed a uniform model of the Moho density contrast. Here we generalize this concept for the variable Moho density contrast and compare the results of these two methods. We incorporate the global density model of the upper (most) mantle in the definition of the variable Moho density contrast. The density heterogeneities within deeper mantle structures are disregarded, because of the absence of a reliable 3D mantle density model. In the numerical experiment, we determine the Moho depths globally by using recent gravity and crustal structure models. The gravimetric results obtained on the basis of adopting uniform and variable models of the Moho density interface are validated against the seismic model.

\section{Theoretical Model}

Gravimetric determination of crustal thickness comprises, in principle, two numerical procedures 
(Tenzer and Chen 2014a). Gravimetric forward modeling is first used to compute the gravity data (i.e., the consolidated crust-stripped gravity disturbances), which are highly spatially correlated with the Moho geometry (cf. Tenzer et al. 2009a, b, 2012a, b). The compensation attraction is then subtracted from these gravity data to obtain the residual gravity data (i.e., the complete crust-stripped gravity disturbances). These residual gravity data are used for a determination of the Moho depth by solving the inverse gravimetric problem. In this study, we utilize the expressions for gravimetric forward and inverse modeling in a frequency domain.

We define two numerical schemes for the gravimetric Moho modeling, assuming that the Moho density contrast is either constant or variable. These two density contrast models are used to define the compensation attraction and subsequently in solving the gravimetric inverse problem.

\subsection{Gravimetric Inverse Problem (for a Constant Density Contrast)}

Tenzer and Chen (2014a) formulated the gravimetric inverse problem of finding the Moho depth while assuming a constant value of the Moho density contrast $\Delta \rho^{\mathrm{c} / \mathrm{m}}$. They derived the linearized observation equation in the form:

$$
\delta g^{m}(r, \Omega)=\frac{\mathrm{GM}}{R^{2}} \sum_{n=0}^{\bar{n}}\left(\frac{R}{r}\right)^{n+2} \frac{n+1}{2 n+1} \sum_{m=-n}^{n} F_{n, m}^{\delta D} Y_{n, m}(\Omega),
$$

where $\delta g^{m}$ is the complete crust-stripped gravity disturbance (defined in the sect. 2.3), $\mathrm{GM}=$ $3,986,005 \times 10^{8} \mathrm{~m}^{3} \mathrm{~s}^{-2}$ is the geocentric gravitational constant, $R=6,371 \times 10^{3} \mathrm{~m}$ is the Earth's mean radius, $F_{n, m}^{\delta D}$ are the Moho-depth correction coefficients, $Y_{n, m}$ are the surface spherical harmonic functions of degree $n$ and order $m$, and $\bar{n}$ is the maximum degree of spherical harmonics. The 3D position is defined in the spherical coordinate system $(r, \Omega)$, where $r$ is the spherical radius and $\Omega=(\phi, \lambda)$ denotes the spherical direction with the spherical latitude $\phi$ and longitude $\lambda$. The spatial form of the linearized observation equation was derived by TENZER and CHEN (2014b). The coefficients $F_{n, m}^{\delta D}$ in Eq. (1) are given by:

$$
F_{n, m}^{\delta D}=\frac{3}{\bar{\rho}^{\text {Earth }}} \sum_{k=0}^{n+2}\left(\begin{array}{c}
n+2 \\
k
\end{array}\right) \frac{(-1)^{k}}{R^{k+1}} \delta D_{n, m}^{(k)},
$$

where $\bar{\rho}^{\text {Earth }}=5,500 \mathrm{~kg} \mathrm{~m}^{-3}$ is the Earth's mean mass density (NovÁK 2010). The coefficients $\left\{\delta D_{n, m}^{(k)}: k=0,1,2, \ldots\right\}$ are given by:

$$
\begin{aligned}
\delta D_{n}^{(k)} & =\frac{2 n+1}{4 \pi} \Delta \rho^{\mathrm{c} / \mathrm{m}} \iint_{\Phi} \mathrm{D}_{0}^{\mathrm{k}}\left(\Omega^{\prime}\right) \delta \mathrm{D}\left(\Omega^{\prime}\right) \mathrm{P}_{\mathrm{n}}(\mathrm{t}) \mathrm{d} \Omega^{\prime} \\
& =\sum_{m=-n}^{n} \delta D_{n, m}^{(k)} Y_{n, m}(\Omega)
\end{aligned}
$$

where $P_{n}$ is the Legendre polynomial of degree $n$, the argument $t=\cos \psi$ is defined for the spherical distance $\psi, d \Omega^{\prime}=\cos \phi^{\prime} d \phi^{\prime} d \lambda^{\prime}$ is the infinitesimal surface element on the unit sphere, and $\Phi=$ $\left\{\Omega^{\prime}=\left(\phi^{\prime}, \lambda^{\prime}\right): \phi^{\prime} \in[-\pi / 2, \pi / 2] \wedge \lambda^{\prime} \in[0,2 \pi)\right\}$ is the full spatial angle.

The linearized observation equation in Eq. (1) defines the relationship between the input gravity data $\delta g^{m}$ and the unknown (and sought) Moho-depth correction terms $\delta D^{\prime} \equiv \delta D\left(\Omega^{\prime}\right)$. The coefficients $F_{n, m}^{\delta D}$, which form the design matrix, are generated by using the a-priori Moho depths $D_{0}^{\prime} \equiv D_{0}\left(\Omega^{\prime}\right)$ (typically obtained from an available seismic model) in accordance with Eqs. (2) and (3). The Moho-depth corrections $\delta D^{\prime}$ are found by solving the gravimetric inverse problem. Application of $\delta D^{\prime}$ to the a-priori (initial) Moho model $D_{0}^{\prime}$ yields the final gravimetric result $D^{\prime}$; i.e., $D^{\prime}=D_{0}^{\prime}+\delta D^{\prime}$.

\subsection{Gravimetric Inverse Problem (for a Variable Density Contrast)}

Let us reformulate the gravimetric inverse problem of finding the Moho depth under the assumption of the variable Moho density contrast $\Delta \rho^{\mathrm{c} / \mathrm{m}}$. This Moho density contrast is defined as the difference between the (laterally varying) upper mantle density $\rho^{m}$ and the (constant) reference crustal density $\rho^{\mathrm{c}}$, i.e.

$$
\Delta \rho^{\mathrm{c} / \mathrm{m}}(\Omega)=\rho^{\mathrm{m}}(\Omega)-\rho^{\mathrm{c}} .
$$

By analogy with Eq. (1), we then write:

$$
\delta g^{m, \Delta \rho}(r, \Omega)=\frac{\mathrm{GM}}{R^{2}} \sum_{n=0}^{\bar{n}}\left(\frac{R}{r}\right)^{n+2} \frac{n+1}{2 n+1} \sum_{m=-n}^{n} F_{n, m}^{\Delta \rho \delta \mathrm{D}} Y_{n, m}(\Omega),
$$


where the complete crust-stripped gravity disturbance $\delta g^{m, \Delta \rho}$ is defined for the variable Moho density contrast (discussed in the sect. 2.3). The Moho-depth correction coefficients $F_{n, m}^{\Delta \rho \delta \mathrm{D}}$ are introduced in the form:

$$
F_{n, m}^{\Delta \rho \delta \mathrm{D}}=\frac{3}{\bar{\rho}^{\text {Earth }}} \sum_{k=0}^{n+2}\left(\begin{array}{c}
n+2 \\
k
\end{array}\right) \frac{(-1)^{k}}{R^{k+1}}\left(\Delta \rho^{\mathrm{c} / \mathrm{m}} \delta \mathrm{D}\right)_{n, m}^{(k)},
$$

where the coefficients $\left\{(\Delta \rho \delta \mathrm{D})_{n, m}^{(k)}: k=0,1,2, \ldots\right\}$ are evaluated by discretizing the integral convolution:

$$
\begin{aligned}
(\Delta \rho \delta \mathrm{D})_{n}^{(k)} & =\frac{2 n+1}{4 \pi} \iint_{\Phi} \Delta \rho^{\mathrm{c} / \mathrm{m}}\left(\Omega^{\prime}\right) \mathrm{D}_{0}^{\mathrm{k}}\left(\Omega^{\prime}\right) \delta \mathrm{D}\left(\Omega^{\prime}\right) \mathrm{P}_{\mathrm{n}}(\mathrm{t}) \mathrm{d} \Omega^{\prime} \\
& =\sum_{m=-n}^{n}(\Delta \rho \delta \mathrm{D})_{n, m}^{(k)} Y_{n, m}(\Omega) .
\end{aligned}
$$

The coefficients $F_{n, m}^{\Delta \rho \delta \mathrm{D}}$ of the design matrix are generated from the a-priori Moho depths $D_{0}^{\prime}$ and the (laterally varying) values of the Moho density contrast $\Delta \rho^{\mathrm{c} / \mathrm{m}}$ in accordance with Eqs. (6) and (7). The inverse solution of a system of observation equations (defined in Eq. 5) yields the Moho-depth correction terms $\delta D^{\prime}$.

\subsection{Gravimetric Forward Modeling}

Computation of the complete crust-stripped gravity disturbances $\delta g^{m}$ in Eq. (1) is realized in two steps. First, the consolidated crust-stripped gravity disturbances $\delta g^{\text {cs }}$ are obtained from the gravity disturbances $\delta g$ by applying the topographic correction and the stripping gravity corrections due to major known anomalous crustal density structures. This computation is realized in accordance with the following scheme (TENZER et al. 2012b):

$$
\delta g^{\mathrm{cs}}=\delta g-g^{t}+g^{b}+g^{i}+g^{s}+g^{c},
$$

where $g^{t}$ is the topographic gravity correction, and $g^{b}$, $g^{i}, g^{s}$, and $g^{c}$ are, respectively, the stripping gravity corrections as a result of the ocean (bathymetry), ice, sediments, and remaining anomalous density structures within the consolidated (crystalline) crust.

Application of the compensation attraction $g^{\mathrm{cmp}}$ to the values of $\delta g^{\mathrm{cs}}$ yields the complete crust-stripped gravity disturbances $\delta g^{m}$ (TENZER et al. 2012b)

$$
\delta g^{m}=\delta g^{\mathrm{cs}}-g^{\mathrm{cmp}} .
$$

By analogy with Eq. (9), the complete cruststripped gravity disturbances $\delta g^{m, \Delta \rho}$, used as the input gravity data for solving the gravimetric inverse problem in Eq. (5), are obtained from the consolidated crust-stripped gravity disturbances $\delta g^{\mathrm{cs}}$ after applying the compensation attraction $g^{\mathrm{cmp}, \Delta \rho}$. This compensation attraction is defined for the variable Moho density contrast $\Delta \rho^{\mathrm{c} / \mathrm{m}}$ (Eq. 4). The expressions for $\delta g, \delta g^{\mathrm{cs}}, g^{\mathrm{cmp}}$ and $g^{\mathrm{cmp}, \Delta \rho}$ are reviewed next.

\subsubsection{Consolidated Crust-stripped Gravity Disturbances}

The gravity disturbance $\delta g$ at a point $(r, \Omega)$ is defined as (Heiskanen and Moritz 1967):

$$
\delta g(r, \Omega)=\frac{\mathrm{GM}}{R^{2}} \sum_{n=0}^{\bar{n}} \sum_{m=-n}^{n}\left(\frac{R}{r}\right)^{n+2}(n+1) T_{n, m} Y_{n, m}(\Omega),
$$

where $T_{n, m}$ are the numerical coefficients, which describe the disturbing gravity potential $T$ (i.e., the difference between the Earth's gravity potential and normal gravity potentials). These coefficients are obtained from the coefficients of a global geopotential model after subtracting the spherical harmonic coefficients of the normal gravity field.

The gravity corrections applied in Eq. (8) are computed by use of the numerical scheme developed by Tenzer et al. (2012a). This numerical scheme utilizes the expression for gravitational attraction $g$ (defined as a negative radial derivative of the respective gravitational potential $V$; i.e., $g=-\partial V / \partial r)$ generated by an arbitrary volumetric mass layer with a variable depth and thickness while having laterally distributed vertical mass density variations. The gravity correction $g$ at a point $(r, \Omega)$ is computed as:

$$
g(r, \Omega)=\frac{\mathrm{GM}}{R^{2}} \sum_{n=0}^{\bar{n}} \sum_{m=-n}^{n}\left(\frac{R}{r}\right)^{n+2}(n+1) V_{n, m} Y_{n, m}(\Omega),
$$

where the potential coefficients $V_{n, m}$ are given by:

$$
V_{n, m}=\frac{3}{\bar{\rho}^{\operatorname{Earth}}(2 n+1)} \sum_{i=0}^{I}\left(\mathrm{Fl}_{n, m}^{(i)}-\mathrm{Fu}_{n, m}^{(i)}\right) .
$$


The numerical coefficients $\left\{\mathrm{Fl}_{n, m}^{(i)}, \mathrm{Fu}_{n, m}^{(i)}: i=\right.$ $0,1, \ldots, I\}$ in Eq. (12) are given by:

$$
\mathrm{Fl}_{n, m}^{(i)}=\sum_{k=0}^{n+2}\left(\begin{array}{c}
n+2 \\
k
\end{array}\right) \frac{(-1)^{k}}{k+1+i} \frac{L_{n, m}^{(k+1+i)}}{R^{k+1}},
$$

and

$$
\mathrm{Fu}_{n, m}^{(i)}=\sum_{k=0}^{n+2}\left(\begin{array}{c}
n+2 \\
k
\end{array}\right) \frac{(-1)^{k}}{k+1+i} \frac{U_{n, m}^{(k+1+i)}}{R^{k+1}} .
$$

The terms $\sum_{m=-n}^{n} L_{n, m} Y_{n, m}$ and $\sum_{m=-n}^{n} U_{n, m} Y_{n, m}$ define the spherical lower-bound and upper-bound laterally distributed radial density variation functions $L_{n}$ and $U_{n}$ of degree $n$, respectively. These spherical functions and their higher-order terms $\left\{L_{n}^{(k+1+i)}\right.$, $\left.U_{n}^{(k+1+i)}: k=0,1, \ldots, n+2 ; i=1,2, \ldots, I\right\}$ are defined by:

$$
\begin{aligned}
& L_{n}^{(k+1+i)} \\
& = \begin{cases}\frac{2 n+1}{4 \pi} \iint_{\Phi} \rho\left(D_{U}, \Omega^{\prime}\right) D_{L}^{k+1}\left(\Omega^{\prime}\right) P_{n}(t) \mathrm{d} \Omega^{\prime} & \\
=\sum_{m=-n}^{n} L_{n, m}^{(k+1)} Y_{n, m}(\Omega) & i=0 \\
\frac{2 n+1}{4 \pi} \iint_{\Phi} \beta\left(\Omega^{\prime}\right) a_{i}\left(\Omega^{\prime}\right) D_{L}^{k+1+i}\left(\Omega^{\prime}\right) P_{n}(t) \mathrm{d} \Omega^{\prime} \\
=\sum_{m=-n}^{n} L_{n, m}^{(k+1+i)} Y_{n, m}(\Omega) & i=1,2, \ldots, I\end{cases}
\end{aligned}
$$

and

$$
\begin{aligned}
& U_{n}^{(k+1+i)}
\end{aligned}
$$

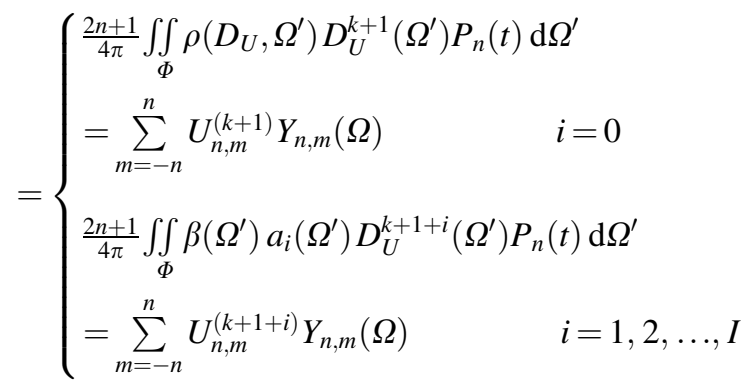

For a specific volumetric layer, the mass density $\rho$ is either constant $\rho$, laterally-varying, $\rho\left(\Omega^{\prime}\right)$ or-the most general case-approximated by the laterally distributed radial density variation model by using the following polynomial function (for each lateral column):

$$
\begin{aligned}
\rho\left(r^{\prime}, \Omega^{\prime}\right)= & \rho\left(D_{U}, \Omega^{\prime}\right) \\
& +\beta\left(\Omega^{\prime}\right) \sum_{i=1}^{I} \alpha_{i}\left(\Omega^{\prime}\right)\left(R-r^{\prime}\right)^{i},
\end{aligned}
$$

$$
\text { for } \quad R-D_{U}\left(\Omega^{\prime}\right) \geq r^{\prime}>R-D_{L}\left(\Omega^{\prime}\right),
$$

where a nominal value of the lateral density $\rho\left(D_{U}, \Omega^{\prime}\right)$ is stipulated at depth $D_{U}$ and location $\Omega^{\prime}$. This density distribution model describes the radial density variation by means of the coefficients $\left\{\alpha_{i}: i=1,2, \ldots, I\right\}$ and $\beta$ within a volumetric mass layer at a location $\Omega^{\prime}$. Alternatively, when modeling the gravitational field of anomalous mass density structures, the density contrast $\Delta \rho\left(\mathrm{r}^{\prime}, \Omega^{\prime}\right)$ of a volumetric mass layer relative to the reference crustal density $\rho^{c}$ is defined as:

$$
\begin{aligned}
& \begin{aligned}
\Delta \rho\left(\mathrm{r}^{\prime}, \Omega^{\prime}\right)= & \rho\left(\mathrm{r}^{\prime}, \Omega^{\prime}\right)-\rho^{\mathrm{c}} \\
= & \Delta \rho\left(\mathrm{D}_{\mathrm{U}}, \Omega^{\prime}\right) \\
& +\beta\left(\Omega^{\prime}\right) \sum_{\mathrm{i}=1}^{\mathrm{I}} \mathrm{a}_{\mathrm{i}}\left(\Omega^{\prime}\right)\left(\mathrm{R}-\mathrm{r}^{\prime}\right)^{\mathrm{i}},
\end{aligned} \\
& \text { for } \quad R-D_{U}\left(\Omega^{\prime}\right) \geq r^{\prime}>R-D_{L}\left(\Omega^{\prime}\right),
\end{aligned}
$$

where $\Delta \rho\left(\mathrm{D}_{\mathrm{U}}, \Omega^{\prime}\right)$ is a nominal value of the lateral density contrast.

From Eqs. (10) and (11), the spectral representation of the consolidated crust-stripped gravity disturbance $\delta g^{\mathrm{cs}}$ is given by:

$$
\delta g^{\mathrm{cs}}(r, \Omega)=\frac{\mathrm{GM}}{R^{2}} \sum_{n=0}^{\bar{n}} \sum_{m=-n}^{n}\left(\frac{R}{r}\right)^{n+2}(n+1) T_{n, m}^{\mathrm{cs}} Y_{n, m}(\Omega),
$$

where the potential coefficients $T_{n, m}^{\mathrm{cs}}$ consist of the following components:

$$
T_{n, m}^{\mathrm{cs}}=T_{n, m}-V_{n, m}^{t}+V_{n, m}^{b}+V_{n, m}^{i}+V_{n, m}^{s}+V_{n, m}^{c} .
$$

Spherical harmonic analysis is used to generate the gravitational potential coefficients of the topography and density contrasts of the ocean, ice, sediments, and consolidated crust $\left(V_{n, m}^{t}, V_{n, m}^{b}, V_{n, m}^{i}, V_{n, m}^{s}\right.$ and $\left.V_{n, m}^{c}\right)$ to a specific degree of spherical harmonics by use of an 
available global crustal structure model (i.e., typically provided by means of discrete density, depth, and thickness data) in accordance with Eqs. (12-18).

\subsubsection{Compensation Attraction (for a Constant Density Contrast)}

Tenzer and Chen (2014a) defined the compensation attraction $g^{\mathrm{cmp}}$ for the constant Moho density contrast $\Delta \rho^{\mathrm{c} / \mathrm{m}}$ in the form:

$g^{\mathrm{cmp}}(r, \Omega)=\frac{\mathrm{GM}}{R^{2}} \sum_{n=0}^{\bar{n}} \frac{1}{2 n+1}\left(\frac{R}{r}\right)^{n+3} \frac{n+1}{n+3} \sum_{m=-n}^{n} F_{n, m}^{D} Y_{n, m}(\Omega)$,

where the numerical coefficients $F_{n, m}^{D}$ are given by:

$$
F_{n, m}^{D}=-\frac{3}{\bar{\rho}^{\text {Earth }}} \sum_{k=1}^{n+3}\left(\begin{array}{c}
n+3 \\
k
\end{array}\right) \frac{(-1)^{k}}{R^{k}} D_{n, m}^{(k)} .
$$

The Moho-depth spherical functions $D_{n}$ and their higher-order terms $\left\{D_{n}^{(k)}: k=2,3, \ldots\right\}$ are defined as:

$$
\begin{aligned}
D_{n} & =\frac{2 n+1}{4 \pi} \Delta \rho^{\mathrm{c} / \mathrm{m}} \iint_{\Phi} \mathrm{D}_{0}\left(\Omega^{\prime}\right) \mathrm{P}_{\mathrm{n}}(\mathrm{t}) \mathrm{d} \Omega^{\prime} \\
& =\sum_{\mathrm{m}=-\mathrm{n}}^{\mathrm{n}} \mathrm{D}_{\mathrm{n}, \mathrm{m}} \mathrm{Y}_{\mathrm{n}, \mathrm{m}}(\Omega),
\end{aligned}
$$

and

$$
\begin{aligned}
D_{n}^{(k)} & =\frac{2 n+1}{4 \pi} \Delta \rho^{\mathrm{c} / \mathrm{m}} \iint_{\Phi} \mathrm{D}_{0}^{\mathrm{k}}\left(\Omega^{\prime}\right) \mathrm{P}_{\mathrm{n}}(\mathrm{t}) \mathrm{d} \Omega^{\prime} \\
& =\sum_{\mathrm{m}=-\mathrm{n}}^{\mathrm{n}} \mathrm{D}_{\mathrm{n}, \mathrm{m}}^{(\mathrm{k})} \mathrm{Y}_{\mathrm{n}, \mathrm{m}}(\Omega),
\end{aligned}
$$

where the Moho-depth coefficients $D_{n, m}$ are generated from the a-priori Moho depths $D_{0}^{\prime}$.

\subsubsection{Compensation Attraction (for a Variable Density Contrast)}

By analogy with Eq. (21), we define the compensation attraction $g^{\mathrm{cmp}, \Delta \rho}$ for the variable Moho density contrast $\Delta \rho^{\mathrm{c} / \mathrm{m}}$ in the form:

$$
\begin{aligned}
g^{\mathrm{cmp}, \Delta \rho}(r, \Omega)= & \frac{\mathrm{GM}}{R^{2}} \sum_{n=0}^{\bar{n}} \frac{1}{2 n+1}\left(\frac{R}{r}\right)^{n+3} \frac{n+1}{n+3} \\
& \times \sum_{m=-n}^{n} F_{n, m}^{\Delta \rho \mathrm{D}} Y_{n, m}(\Omega),
\end{aligned}
$$

where the numerical coefficients $F_{n, m}^{\Delta \rho \mathrm{D}}$ are given by:

$$
F_{n, m}^{\Delta \rho \mathrm{D}}=-\frac{3}{\bar{\rho}^{\text {Earth }}} \sum_{k=1}^{n+3}\left(\begin{array}{c}
n+3 \\
k
\end{array}\right) \frac{(-1)^{k}}{R^{k}}(\Delta \rho \mathrm{D})_{n, m}^{(k)} .
$$

The Moho-depth spherical functions $(\Delta \rho \mathrm{D})_{n}$ and their higher-order terms $\left\{(\Delta \rho \mathrm{D})_{n}^{(k)}: k=2,3, \ldots\right\}$ are given by:

$$
\begin{aligned}
(\Delta \rho \mathrm{D})_{n} & =\frac{2 n+1}{4 \pi} \iint_{\Phi} \Delta \rho^{\mathrm{c} / \mathrm{m}}\left(\Omega^{\prime}\right) \mathrm{D}_{0}\left(\Omega^{\prime}\right) \mathrm{P}_{\mathrm{n}}(\mathrm{t}) \mathrm{d} \Omega^{\prime} \\
& =\sum_{m=-n}^{n}(\Delta \rho \mathrm{D})_{n, m} Y_{n, m}(\Omega),
\end{aligned}
$$

and

$$
\begin{aligned}
(\Delta \rho \mathrm{D})_{n}^{(k)} & =\frac{2 n+1}{4 \pi} \iint_{\Phi} \Delta \rho^{\mathrm{c} / \mathrm{m}}\left(\Omega^{\prime}\right) \mathrm{D}_{0}^{\mathrm{k}}\left(\Omega^{\prime}\right) \mathrm{P}_{\mathrm{n}}(\mathrm{t}) \mathrm{d} \Omega^{\prime} \\
& =\sum_{m=-n}^{n}(\Delta \rho \mathrm{D})_{n, m}^{(k)} Y_{n, m}(\Omega)
\end{aligned}
$$

The coefficients $(\Delta \rho \mathrm{D})_{n, m}$ and their higherorder terms $\left\{(\Delta \rho \mathrm{D})_{n, m}^{(k)}: k=2,3, \ldots\right\}$ are generated from the a-priori Moho depths $D_{0}^{\prime}$ and the (laterally varying) values of the Moho density contrast $\Delta \rho^{\mathrm{c} / \mathrm{m}}$.

\section{Results and Analysis}

Two schemes for determination of crustal thickness based on adopting uniform and variable models of the Moho density contrast were used to assess the gravitational effect of the upper mantle density (which is implicitly incorporated in definition of the variable Moho density contrast) on the Moho geometry. The gravity field quantities were calculated globally on a $1 \times 1$ arc-deg surface grid. The Moho depths were determined on a $1 \times 1$ arc-deg global grid, which is identical with a position of gravity points. The gravity field quantities and the Moho geometry were determined with a spectral resolution complete to degree 180 of spherical harmonics (which corresponds to a half-wavelength of 1 arc-deg, or approximately $100 \mathrm{~km}$ on equator). 


\subsection{Consolidated Crust-stripped Gravity Disturbances}

The expressions for the gravimetric forward modeling were used to compute the gravity disturbances (Eq. 10) and the gravity corrections because of major known crustal density structures (Eqs. 11-18). The consolidated crust-stripped gravity disturbances were then obtained from the gravity disturbances after applying these gravity corrections in accordance with Eq. (8). The gravity disturbances were generated by using the coefficients of the global gravitational model GOCO-03c (MAYER-GUERR et al. 2012; Jin et al. 2013). The spherical harmonic terms of the normal gravity field were computed in accordance with data from the Geodetic Reference System 1980 (GRS-80; MoRITZ 2000). The topographic correction and the stripping gravity corrections due to bathymetry, ice, sediment, and consolidated crustal layers were generated from the coefficients of the Earth's spectral crustal model (ESCM180). The ESCM180 coefficients were compiled from the CRUST1.0 global seismic crustal model (LASKE et al. 2012) by incorporating additional global datasets for the topography, bathymetry, polar ice sheets, and geoid surface (cf. CHEN and TENZER 2014). Moreover, the depth-dependent seawater density was used to define the ocean density contrast (GLADKIKH and Tenzer 2012; Tenzer et al. 2012e). The density contrasts were taken relative to the reference crustal density of 2,670 $\mathrm{kg} \mathrm{m}^{-3}$ (Hinze 2003).

Global results for topographic and crust components stripping gravity corrections and the respective gravity disturbances corrected for these effects have been presented and discussed by Tenzer and Vajda (2009a). Here we present only the final result of this numerical procedure (Fig. 1). The consolidated cruststripped gravity disturbances vary globally between -956 and $514 \mathrm{mGal}$, with a mean of $36 \mathrm{mGal}$ and a standard deviation of $277 \mathrm{mGal}$. As seen in Fig. 1, these gravity disturbances are mostly positive over oceans and negative over continents. The maxima correspond to locations of the oceanic subduction zones. The corresponding minima over oceans are along the mid-oceanic ridges. The most pronounced feature of the gravity map is the global tectonic configuration of boundaries between the oceanic and continental lithospheric plates, which is distinctively marked by small (absolute) values of these gravity disturbances. The largest negative gravity disturbances on land apply over orogens of the Tibetan Plateau, Himalayas, and Andes.

\subsection{Moho Density Contrast}

We estimated the average value of the Moho density contrast by minimizing a spatial correlation between the complete crust-stripped gravity data (generated from the ESCM180 coefficients) and CRUST1.0 Moho geometry. Our results revealed that the minimum correlation is obtained for a Moho density contrast $\Delta \rho^{\mathrm{c} / \mathrm{m}}$ of $445 \mathrm{~kg} \mathrm{~m}^{-3}$.

We further evaluated the variable Moho density contrast relative to the reference crustal density of $2,670 \mathrm{~kg} \mathrm{~m}^{-3}$ by using the $1 \times 1$ arc-deg data from the CRUST1.0 upper mantle density model (Fig. 2). As is apparent from statistics in Table 1, the Moho density contrast varies over a relatively large range of $340-790 \mathrm{~kg} \mathrm{~m}^{-3}$. The density contrast shown in Fig. 2 obviously does not represent the real density contrast at the Moho interface (because it is defined relative to a constant crustal density). To illustrate the Moho density contrast more realistically (up to a level of model uncertainties), we used the $1 \times 1$ arc-deg data from the CRUST1.0 lower crust and upper mantle model (Fig. 3, and statistics in Table 1). The density contrast minima mark distinctively the mid-oceanic ridges (i.e., divergent tectonic plate boundaries) and the oceanic subduction zones (i.e., convergent tectonic plate boundaries). The Moho density contrast under the continental crust is typically more pronounced than under the oceanic crust. The density contrast under the oceanic crust is usually less than $350 \mathrm{~kg} \mathrm{~m}^{-3}$, whereas it typically exceeds $400 \mathrm{~kg} \mathrm{~m}^{-3}$ under the continental crust. Substantially smaller values of the Moho density contrast under the continental crust are detected only along the East-African and West-Antarctic rift zones and the continent-to-continent collision zone of the African and Eurasian tectonic plates (along the Mediterranean Sea). The density contrast maxima are under the orogens of the Himalayas, Tibetan Plateau, and Andes. Some regional spatial variations in the Moho density contrast are recognized under the continental crust. For instance, large values of the 


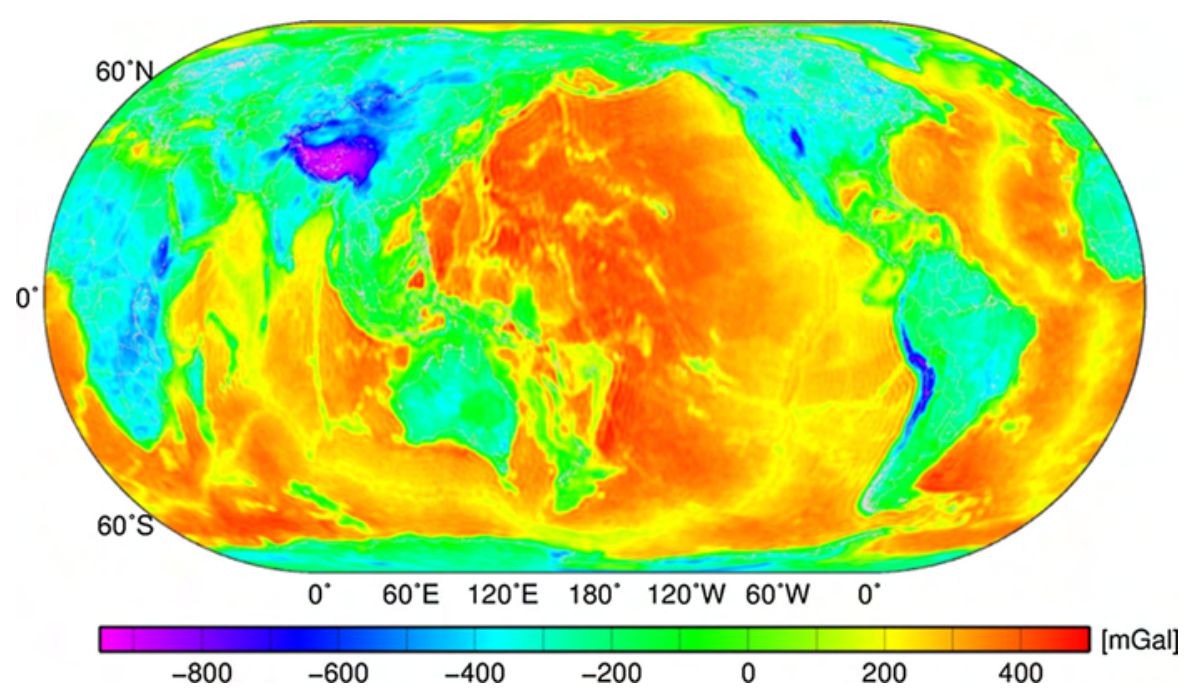

Figure 1

Consolidated crust-stripped gravity disturbances (in $\mathrm{mGal}$ )

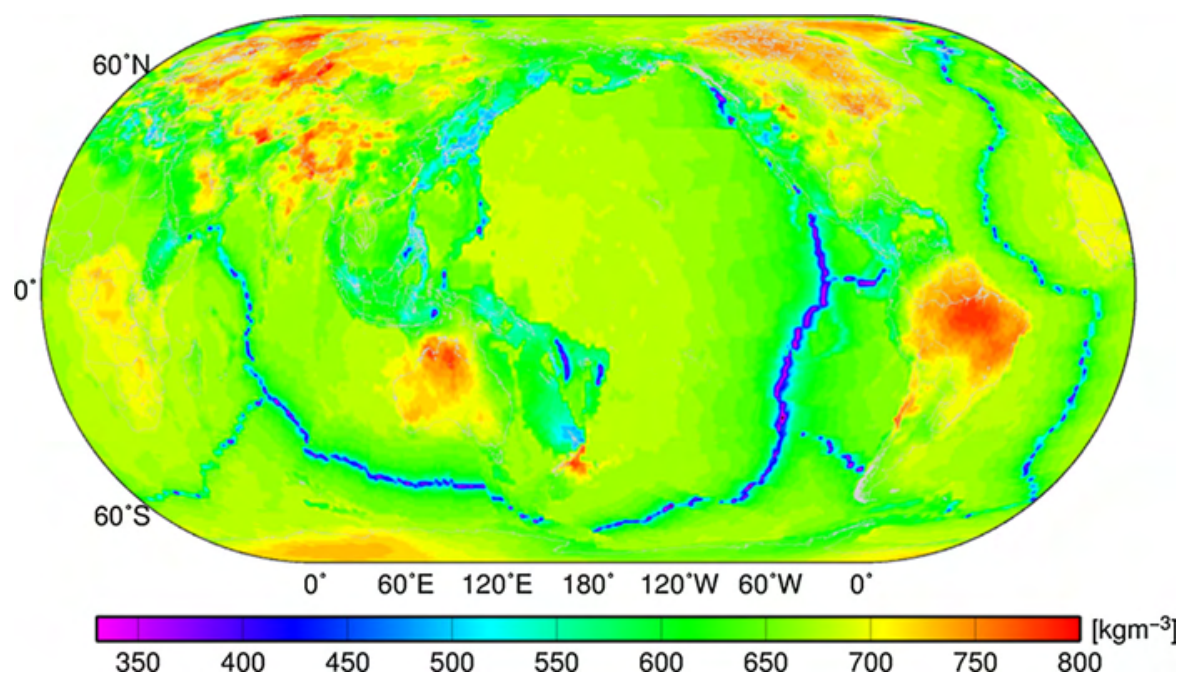

Figure 2

Moho density contrast (in $\mathrm{kg} \mathrm{m}^{-3}$ ) computed relative to the reference crustal density of $2,670 \mathrm{~kg} \mathrm{~m}^{-3}$ using the CRUST1.0 upper mantle density model

Moho density contrast are seen under the cratonic shields and platforms in East Antarctica, North America, Amazonia, North-West Australia, West Africa, Congo, Kalahari, Tanzania, and Fennoscandia.

\subsection{Complete Crust-stripped Gravity Disturbances}

The uniform and variable models of the Moho density contrast were used to compute the compensation attractions in accordance with Eqs. (21-24)
Table 1

Statistics of the CRUST1.0 upper mantle and lower crust density model and the Moho density contrast

\begin{tabular}{lcccl}
\hline CRUST1.0 density & $\begin{array}{l}\text { Min } \\
\left(\mathrm{kg} \mathrm{m}^{-3}\right)\end{array}$ & $\begin{array}{l}\text { Max } \\
\left(\mathrm{kg} \mathrm{m}^{-3}\right)\end{array}$ & $\begin{array}{l}\text { Mean } \\
\left(\mathrm{kg} \mathrm{m}^{-3}\right)\end{array}$ & $\begin{array}{l}\mathrm{STD} \\
\left(\mathrm{kg} \mathrm{m}^{-3}\right)\end{array}$ \\
\hline $\begin{array}{l}\text { Upper mantle- } \\
\quad 3670 \mathrm{kgm}^{-3}\end{array}$ & 340 & 790 & 662 & 49 \\
$\quad$ & & & \\
Lower crust & 2,850 & 3,050 & 3,002 & 66 \\
Upper mantle & 3,010 & 3,460 & 3,332 & 49 \\
Upper mantle- & 10 & 610 & 330 & 92 \\
$\quad$ lower crust & & & & \\
\hline
\end{tabular}



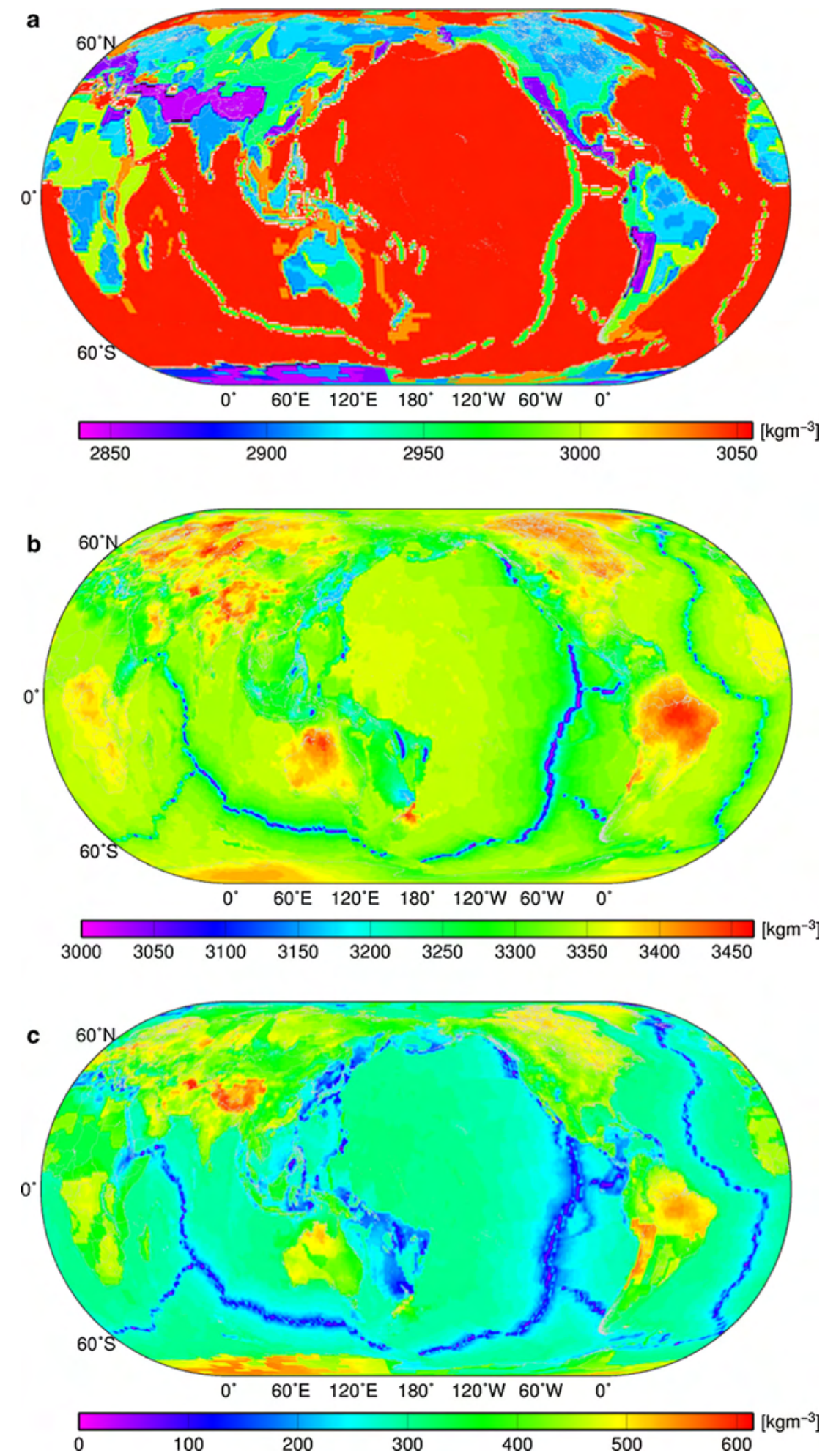

Figure 3

CRUST1.0 density contrast structure: a the lower crust density, $\mathbf{b}$ the upper mantle density, and $\mathbf{c}$ the Moho density contrast (in $\mathrm{kg} \mathrm{m}^{-3}$ ) 

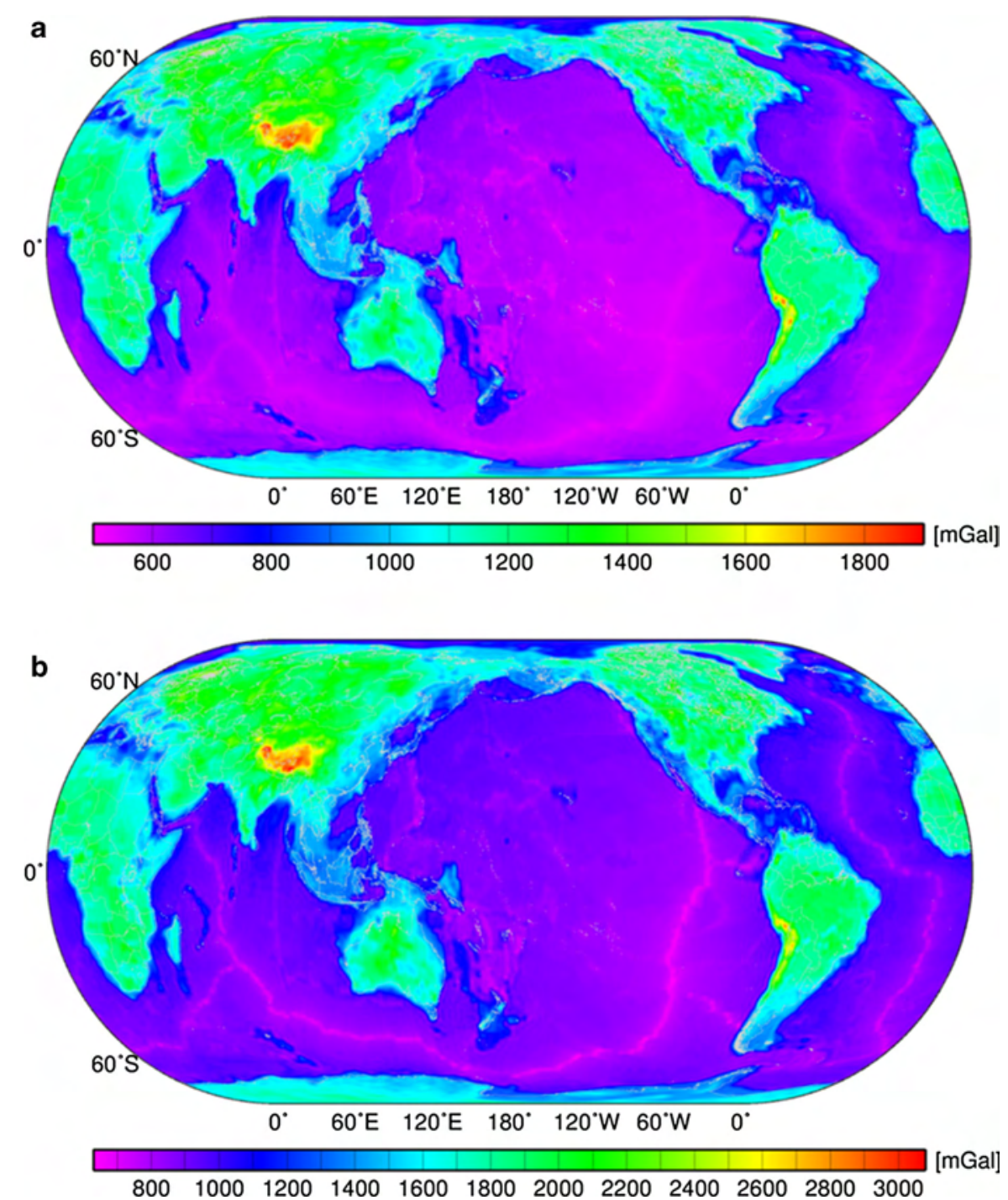

Figure 4

Compensation attraction (in mGal) computed by using the constant (a) and variable (b) Moho density contrast models

and Eqs. (25-28), respectively (Fig. 4, and statistics in Table 2). These two types of the compensation attraction were then used to compute the complete crust-stripped gravity disturbances (Fig. 5, and statistics in Table 3) from the consolidated cruststripped gravity disturbances (shown in Fig. 1). The compensation attraction computed by using the constant Moho density contrast (of $445 \mathrm{~kg} \mathrm{~m}^{-3}$ ) has a range of values of $1,367 \mathrm{mGal}$. The corresponding compensation attraction computed by using the variable Moho density contrast has a substantially larger range of values of 2,450 $\mathrm{mGal}$. The differences between these two types of compensation attraction
Table 2

Statistics of the compensation attractions $g^{\mathrm{cmp}}$ and $g^{\mathrm{cmp}, \Delta \rho}$ computed by using the constant and variable Moho density contrast, respectively

\begin{tabular}{lllll}
\hline $\begin{array}{l}\text { Compensation } \\
\text { attraction }\end{array}$ & $\begin{array}{l}\text { Min } \\
(\mathrm{mGal})\end{array}$ & $\begin{array}{l}\text { Max } \\
(\mathrm{mGal})\end{array}$ & $\begin{array}{l}\text { Mean } \\
(\mathrm{mGal})\end{array}$ & $\begin{array}{l}\text { STD } \\
(\mathrm{mGal})\end{array}$ \\
\hline$g^{\mathrm{cmp}}$ & 503 & 1,870 & 834 & 263 \\
$g^{\mathrm{cmp}, \Delta \rho}$ & 636 & 3,086 & 1,256 & 421 \\
\hline
\end{tabular}

(and consequently the respective values of the complete crust-stripped gravity disturbances) vary between $-1,216$ and $113 \mathrm{mGal}$, with a mean of $421 \mathrm{mGal}$ and a standard deviation of $162 \mathrm{mGal}$. As 

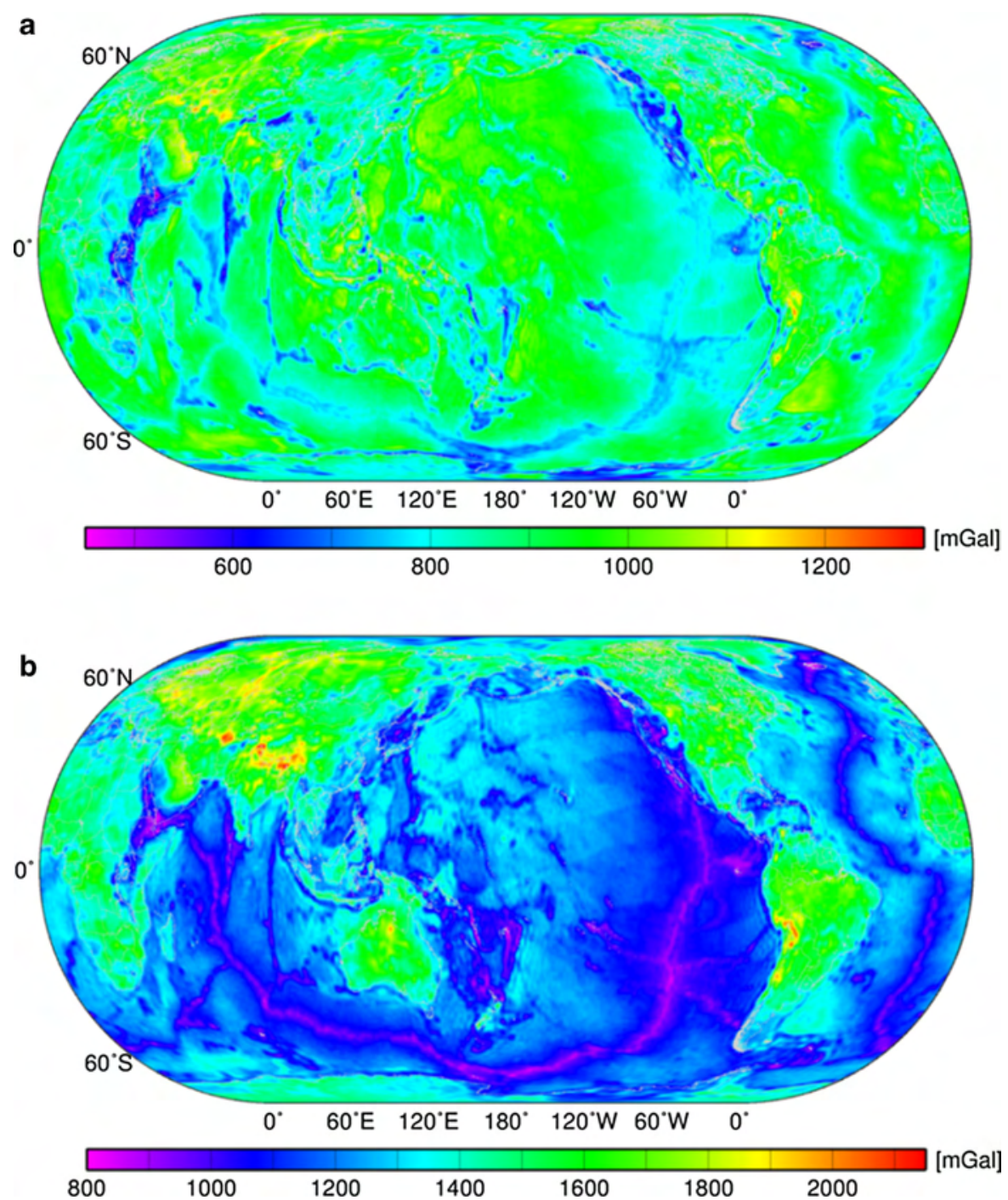

Figure 5

Complete crust-stripped gravity disturbances (in mGal) computed using the constant (a) and variable (b) Moho density contrast models

Table 3

Statistics of the complete crust-stripped gravity disturbances $\delta g^{m}$ and $\delta g^{m, \Delta \rho}$ computed by using the constant and variable Moho density contrast, respectively

\begin{tabular}{llllr}
\hline $\begin{array}{l}\text { Complete crust-stripped } \\
\text { gravity disturbance }\end{array}$ & $\begin{array}{l}\text { Min } \\
(\mathrm{mGal})\end{array}$ & $\begin{array}{l}\text { Max } \\
(\mathrm{mGal})\end{array}$ & $\begin{array}{l}\text { Mean } \\
(\mathrm{mGal})\end{array}$ & $\begin{array}{l}\text { STD } \\
(\mathrm{mGal})\end{array}$ \\
\hline$\delta g^{m}$ & 453 & 1,306 & 871 & 90 \\
$\delta g^{m, \Delta \rho}$ & 809 & 2,166 & 1,292 & 192 \\
\hline
\end{tabular}

is apparent from Fig. 6, the largest differences are under the orogens, where maxima of the compensation attraction (attributed to the largest crustal thickness) are further magnified by large values of the variable Moho density contrast (exceeding $600 \mathrm{~kg} \mathrm{~m}^{-3}$ in these locations).

The complete crust-stripped gravity disturbances comprise mainly the gravitational signal of density heterogeneities within the mantle lithosphere and the sub-lithosphere mantle (including the core-mantle boundary zone; Peltier 2007). The gravitational signature of the lithosphere density structure is, for instance, evident over oceans (Fig. 5). The gravity minima are along the mid-oceanic ridges (and hotspots) and the corresponding gravity maxima are 


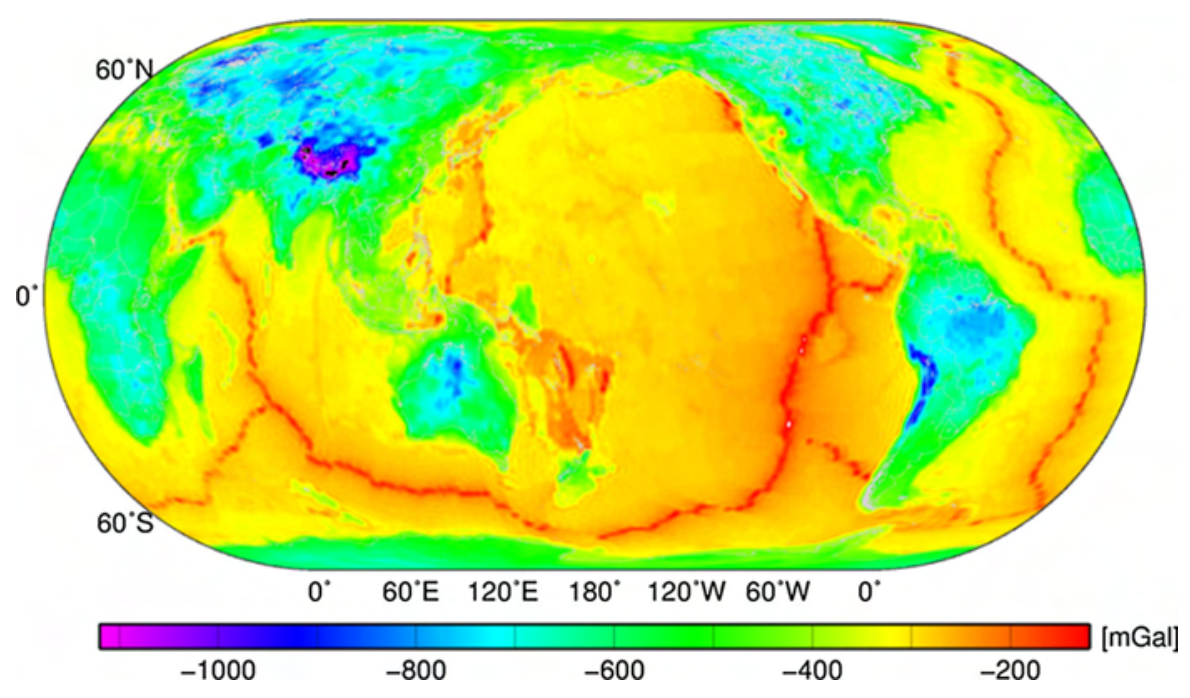

Figure 6

Differences (in mGal) between the complete crust-stripped gravity disturbances (shown in Fig. 5) computed by using the constant and variable Moho density contrast models

along the oceanic subduction zones. These features are attributed to ocean-floor spreading because of mantle convection (i.e., increasing density with age of the oceanic lithosphere; cf. TENZER et al. 2012c). The gravity minima over land distinctively mark the continental rift zones (e.g., the West-Antarctic, EastAfrican, and Baikal rift zones). These gravity minima thus coincide with divergent tectonic plate boundaries. In contrast, the gravity maxima are seen mainly over the orogens of the Himalayas, Tibetan Plateau, and Andes. Both types of consolidated crust-stripped gravity disturbance are everywhere positive. This systematic bias is because of the redundant gravitational signal of (unmodeled) deep mantle density heterogeneities.

\subsection{Moho Geometry}

The complete crust-stripped gravity disturbances (Fig. 5a) were used to determine the Moho depths. Here, we assumed a constant value of the Moho density contrast $\left(455 \mathrm{~kg} \mathrm{~m}^{-3}\right)$. The system of observation equations was formulated in accordance with Eq. (1). We further estimated the Moho geometry from the complete crust-stripped gravity disturbances (Fig. 5b) by assuming variable Moho density contrast. The system of observation equations was, in this case, in accordance with Eq. (5).
The Moho geometry was determined in accordance with the procedure described by TENZER and CHEN (2014a). The inverse solution was performed iteratively by use of a Gauss-Seidel scheme (YounG 1971). A condition of the convergence between results of two successive steps $(k$ and $k+1)$ was $\left\|\delta D_{n, m}^{k+1}-\delta D_{n, m}^{k}\right\|_{2} \leq c$, where $c$ is a limit of convergence. The iteration stopped when the difference between two successive results was $<0.1 \%$. The values of a design matrix were computed by using CRUST1.0 data. The a-priori error model was not applied, because the CRUST1.0 Moho depth and density contrast uncertainties are not known. We used a simple regularization scheme to stabilize the illposed solution. The regularization matrix was set equal to the identity matrix. The selection criterion for finding the optimum regularization variable was based on minimizing the RMS of differences between the gravimetric and seismic models. For the constant Moho density contrast, the best solution $(4.4 \mathrm{~km})$ by means of the RMS fit was obtained by using a regulation variable of $1.8 \times 10^{-7}$. For the variable Moho density contrast, the best RMS fit $(3.0 \mathrm{~km})$ was obtained for the same regulation variable.

The global maps of gravimetric solutions (Fig. 7) revealed a typical pattern of the Moho geometry with enhanced contrast between the thick continental crust and thinner oceanic crust. The largest Moho depths 

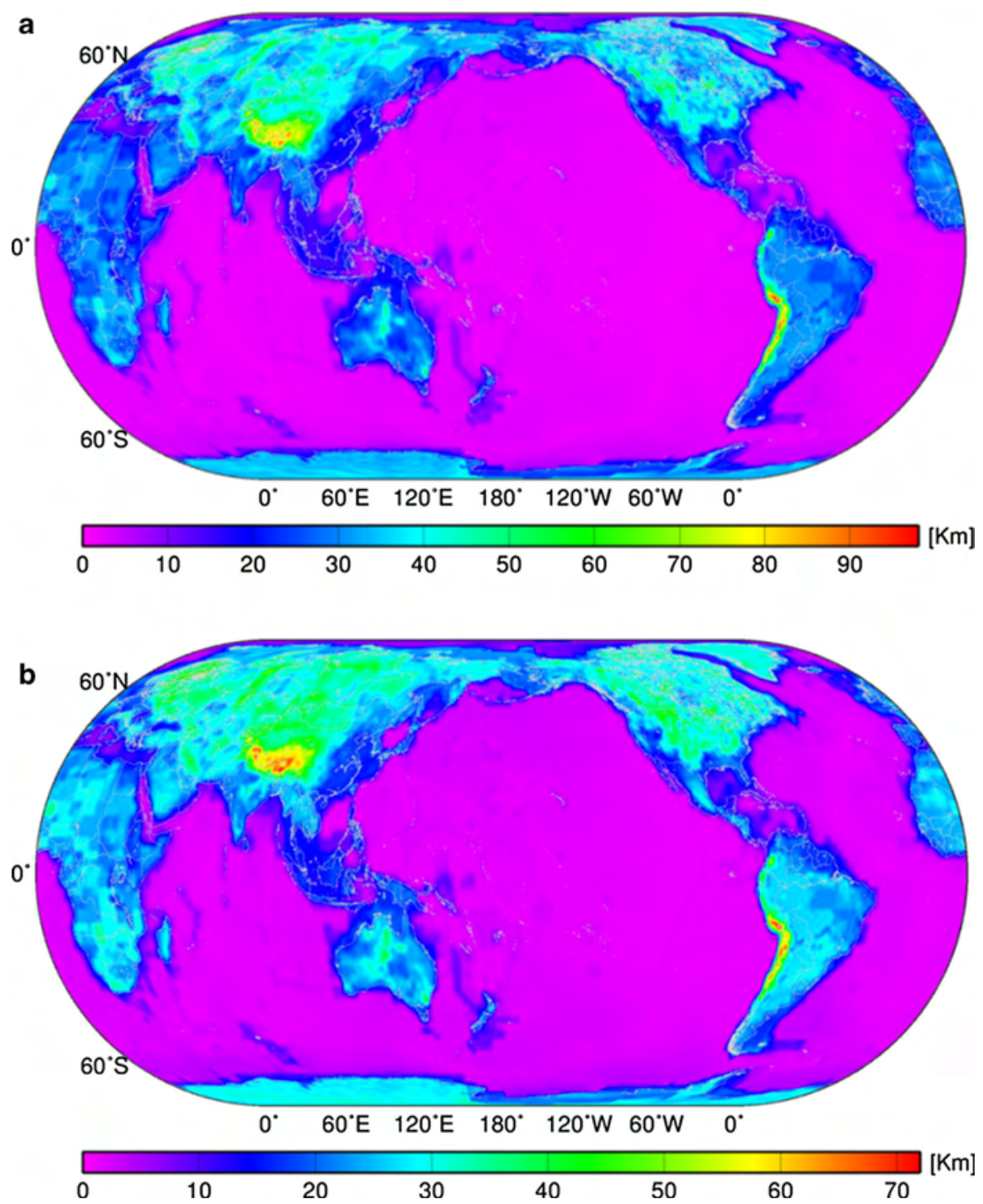

Figure 7

Gravimetric Moho depths (in km) determined by using the constant (a) and variable (b) models of the Moho density contrast models

were confirmed under the Andes and Himalayas with an extension beneath the Tibetan Plateau. Moho depth minima were found under most of the oceanic crust. Comparison of these two solutions, however, revealed some substantial differences (Fig. 8). The range of Moho depths is $97.0 \mathrm{~km}$ (for a uniform model) and $70.9 \mathrm{~km}$ (for a variable model); the statistics are given in Table 4. The largest Moho depth differences were found under orogens (Fig. 8). Moreover, these two gravimetric solutions differ in average values (Table 4). It is also obvious that the minimum Moho depths of $0.9 \mathrm{~km}$ in both results are unrealistically small. Comparison of our gravimetric results with the CRUST1.0 seismic model indicates that these small values are because of the presence of systematic bias attributed to unmodeled deep mantle density heterogeneities (this issue is discussed further in the sect 3.5) (Fig. 9).

\subsection{Validation of Results}

The RMS difference between the gravimetric and seismic Moho depths (for a uniform model) is $4.4 \mathrm{~km}$ (cf. Table 5). The variable Moho density 


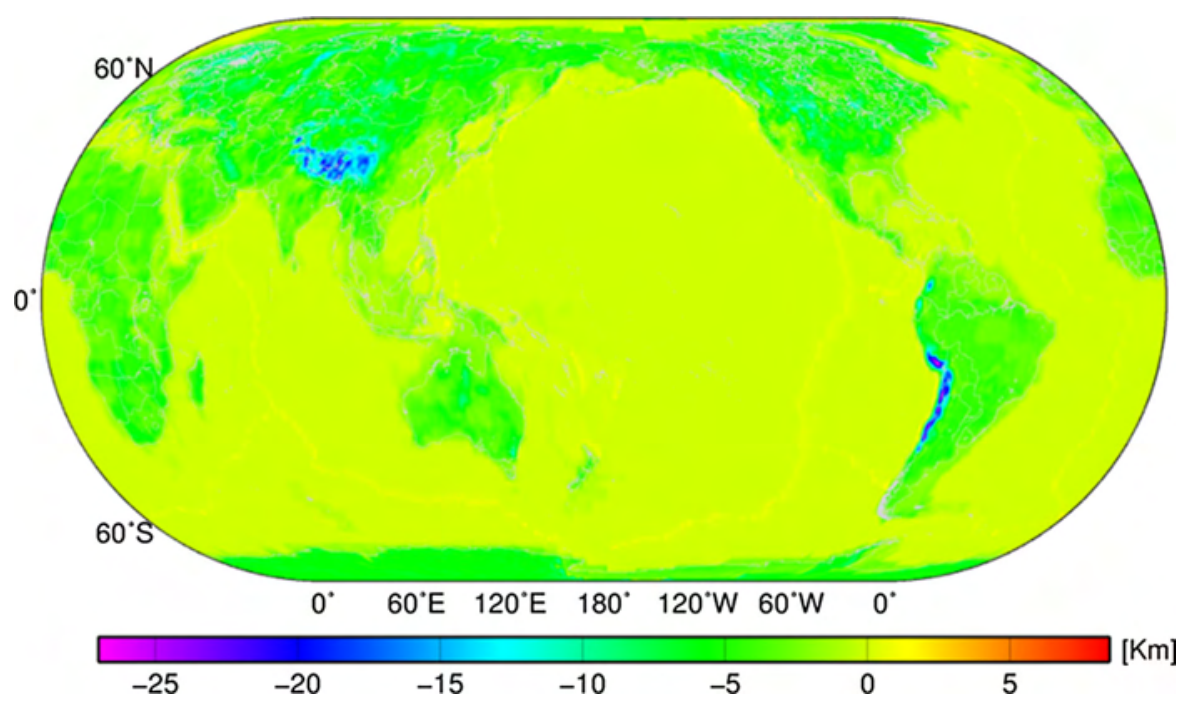

Figure 8

Moho depth differences (in km) between the gravimetric solutions (shown in Fig. 7) determined by using the variable and constant models of the Moho density contrast

Table 4

Statistics of the Moho depths; where D DRUST1.0 are the CRUST1.O Moho depths, and $D$ and $D_{\Delta \rho}$ are the gravimetric Moho depths determined by using the constant and variable Moho density contrast, respectively

\begin{tabular}{lllll}
\hline Moho depth & Min $(\mathrm{km})$ & Max $(\mathrm{km})$ & Mean $(\mathrm{km})$ & STD $(\mathrm{km})$ \\
\hline$D$ & 0.9 & 97.9 & 15.1 & 15.0 \\
$D_{\Delta \rho}$ & 0.9 & 71.8 & 13.2 & 12.4 \\
$D_{\text {CRUST1.0 }}$ & 7.4 & 74.8 & 22.9 & 12.4 \\
\hline
\end{tabular}

contrast improved the RMS fit of the gravimetric solution with the seismic model by more than $30 \%$; the RMS difference is, in this case, only $3.0 \mathrm{~km}$. Moreover, large discrepancies between the gravimetric and seismic models were significantly reduced in some regions (Fig. 10). Both gravimetric solutions are significantly biased relative to the CRUST1.0 seismic model; the mean of the differences is $9.7 \mathrm{~km}$ for the variable model and $7.8 \mathrm{~km}$ for the uniform model. This bias causes unrealistically small Moho depths under the oceanic crustal structures. Moreover, application of the constant Moho density contrast yields large Moho depths beneath orogens of the Tibetan Plateau, Himalayas, and central Andes. Application of the variable density contrast model, on the other hand, improved the agreement between the gravimetric and seismic models for these regions. This bias is attributed to large, systematically positive values of the complete crust-stripped gravity disturbances (Fig. 5). A prevailing long-wavelength pattern in these gravity disturbances was explained by the redundant gravitational signal of (unmodeled) mantle heterogeneities (discussed in the sect. 3.3). There are additional uncertainties in the ESCM180 and CRUST1.0 models, which affect the disagreement between the gravimetric and seismic models.

\subsection{Spectral Analysis}

To investigate the power spectra of the gravity and Moho data (complete to degree 180 of spherical harmonics), we calculated their degree variances and respective cumulative degree variances. This computation was performed for the coefficients $T_{n, m}^{\mathrm{cs}}$ of the consolidated crust-stripped gravity disturbances. The same computation was conducted for the coefficients $T_{n, m}^{m}$ and $T_{n, m}^{m, \Delta \rho}$ of the complete crust-stripped gravity disturbances. The spectral characteristics were also computed for the CRUST1.0 Moho-depth coefficients $D_{n, m}^{\text {CRUST1.0 }}$ and for the gravimetric Moho-depth coefficients $D_{n, m}$ and $D_{n, m}^{\Delta \rho}$ (for the uniform and variable Moho density contrast).

The degree variances of the gravity field $\sigma_{n}^{2}(\delta g)$ and the Moho geometry $\sigma_{n}^{2}(D)$ were calculated in 


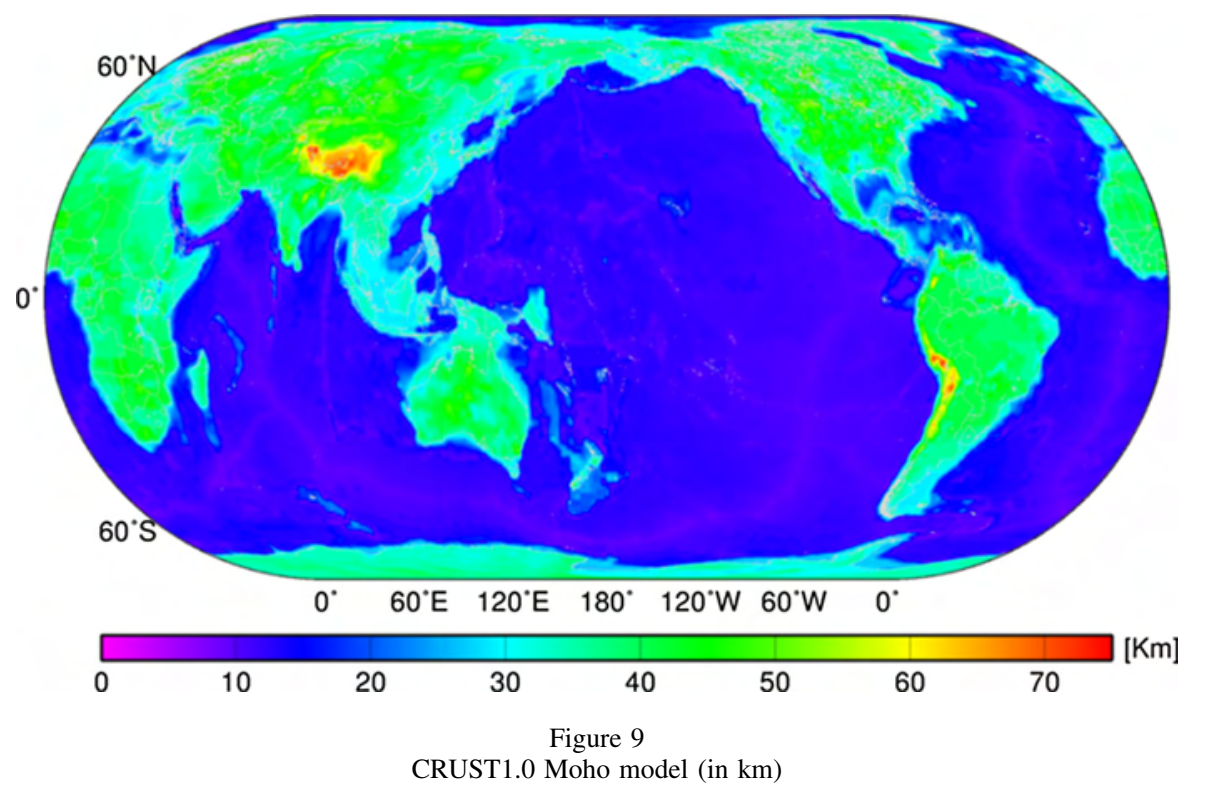

accordance with the generalized Parseval theorem (GELDEREN VAN and Koop 1997):

$$
\sigma_{n}^{2}(\delta g)=\sum_{m=-n}^{n}\left(T_{n, m}\right)^{2}, \sigma_{n}^{2}(D)=\sum_{m=-n}^{n}\left(D_{n, m}\right)^{2}
$$

The corresponding cumulative degree variances were computed from:

$$
\Theta_{N}(\delta g)=\sum_{n=2}^{N} \sigma_{n}^{2}(\delta g), \Theta_{N}(D)=\sum_{n=2}^{N} \sigma_{n}^{2}(D)
$$

We also analyzed spectral correlations of the consolidated and complete crust-stripped gravity disturbances with the Moho geometry. For this purpose, we computed the degree-correlation coefficients between $T_{n, m}$ and $D_{n, m}$ as (PHILlips and LAMBECK 1980):

$$
\theta_{n}^{2}(\delta g, D)=\frac{\sum_{m=-n}^{n}\left(T_{n, m} D_{n, m}\right)}{\sqrt{\sigma_{n}^{2}(\delta g) \sigma_{n}^{2}(D)}},
$$

As is apparent from Fig. 11a, the signal of $T_{n, m}^{\mathrm{cs}}$ has the largest energy at long-to-medium wavelengths $(n<70)$. The degree variances of $T_{n, m}^{\mathrm{cs}}$ and $T_{n, m}^{m, \Delta \rho}$ are very similar at $70<n<100$, whereas the signal of $T_{n, m}^{m, \Delta \rho}$ is slightly more pronounced at $n>100$. The signal of $T_{n, m}^{m}$ has the smallest energy at $n<120$ and becomes similar to $T_{n, m}^{\mathrm{cs}}$ at $n>120$.
Interestingly, the signals of $T_{n, m}^{m}$ and $T_{n, m}^{m, \Delta \rho}$ occur almost completely within the lowest spherical harmonics $(n<3)$ whereas the contribution from the remaining part of the range of gravity $(n \geq 3)$ is much smaller (Fig. 11b).

Both gravimetric Moho solutions $D_{n, m}$ and $D_{n, m}^{\Delta \rho}$ are biased relative to the CRUST1.0 Moho model $D_{n, m}^{\text {CRUST1.0 }}$ at $n=0$ (Fig. 12b). As is apparent from Fig. 12a, the signal of $D_{n, m}^{\Delta \rho}$ is more prominent at $20<n<110$ and becomes similar to $D_{\mathrm{n}, \mathrm{m}}^{\text {CRUST1.0 }}$ at $n>110$. The degree variances of $D_{n, m}$ decrease slightly faster than for $D_{n, m}^{\text {CRUST1.0 }}$ and $D_{n, m}^{\Delta \rho}$ at $n>60$.

Except for $n=0$, the spectral correlations of $T_{n, m}^{\mathrm{cs}}$ with $D_{n, m}, D_{n, m}^{\Delta \rho}$ and $D_{n, m}^{\text {CRUST1.0 }}$ are everywhere negative (Fig. 13a), with the highest (absolute) correlations $(>0.95)$ at $n<5$. The correlation between $T_{n, m}^{\mathrm{cs}}$ and $D_{n, m}^{\text {CRUST1.0 }}$ decreases almost monotonously decreases (in the absolute sense) to approximately -0.25 (at $n>160$ ). In contrast, the correlations of $T_{n, m}^{\mathrm{cs}}$ with $D_{n, m}$ and $D_{n, m}^{\Delta \rho}$ decrease more rapidly (in the absolute sense) at $40<n<110$ and become almost unchanged (approx. -0.25 ) at $n>110$.

The correlation spectra of $T_{n, m}^{m}$ with $D_{n, m}, D_{n, m}^{\Delta \rho}$ and $D_{n, m}^{\text {CRUST1.0 }}$ are very similar (Fig. 13b). At $n<30$, these correlations oscillate around zero, then slightly increase (to approx. 0.2) at $30<n<80$ and remain mostly within $0.2-0.3$ at $n>80$.

The correlation spectra of $T_{n, m}^{m, \Delta \rho}$ with $D_{n, m}, D_{n, m}^{\Delta \rho}$ and $D_{n, m}^{\mathrm{CRUST} 1.0}$ (Fig. 13c) have a different trend than 
the respective correlation spectra of $T_{n, m}^{m}$ (Fig. 13b). The correlations are, in this case, everywhere positive. The largest correlations $(>0.6)$ are at

Table 5

Statistics of the Moho depth differences

\begin{tabular}{llrrl}
\hline $\begin{array}{l}\text { Moho depth } \\
\text { difference }\end{array}$ & $\begin{array}{l}\text { Min } \\
(\mathrm{km})\end{array}$ & $\begin{array}{c}\text { Max } \\
(\mathrm{km})\end{array}$ & $\begin{array}{l}\text { Mean } \\
(\mathrm{km})\end{array}$ & \multicolumn{1}{l}{$\begin{array}{l}\mathrm{RMS} \\
(\mathrm{km})\end{array}$} \\
\hline$D_{\Delta \rho}-D$ & -26.3 & 8.1 & -1.9 & 2.6 \\
$D_{\text {CRUST1.0 }}-D_{\Delta \rho}$ & -11.7 & 30.7 & 9.7 & 3.0 \\
$D_{\text {CRUST1.0 }}-D$ & -34.6 & 29.2 & 7.8 & 4.4 \\
\hline
\end{tabular}

The notation is explained in Table 4 $n<14$. At $n>20$, the correlation spectra oscillate at approximately 0.5 , except for the correlation between $T_{n, m}^{m, \Delta \rho}$ and $D_{n, m}^{\text {CRUST1.0 }}$, which shows some weakening at $n>100$ (to approx. 0.35 at $n=180$ ).

\section{Discussion}

Application of gravity corrections to the GOCO03c gravity disturbances removed the gravitational signal attributed to the topography and to crustal density heterogeneities. The consolidated cruststripped gravity disturbances thus comprise mainly
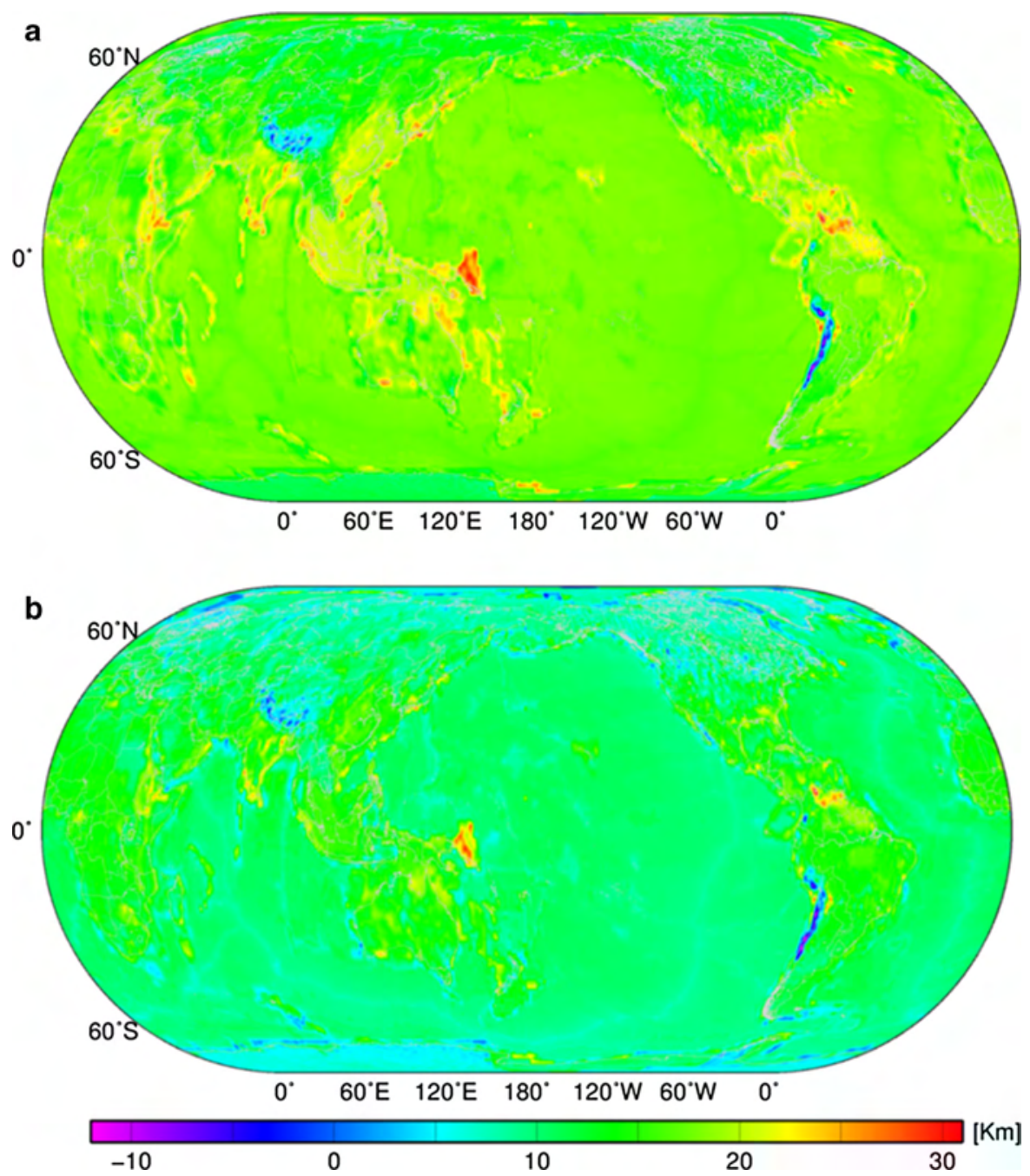

Figure 10

Moho depth differences (in km) between the CRUST1.0 (shown in Fig. 9) and gravimetric solutions (shown in Fig. 7) determined by using the constant (a) and variable (b) Moho density contrast models 

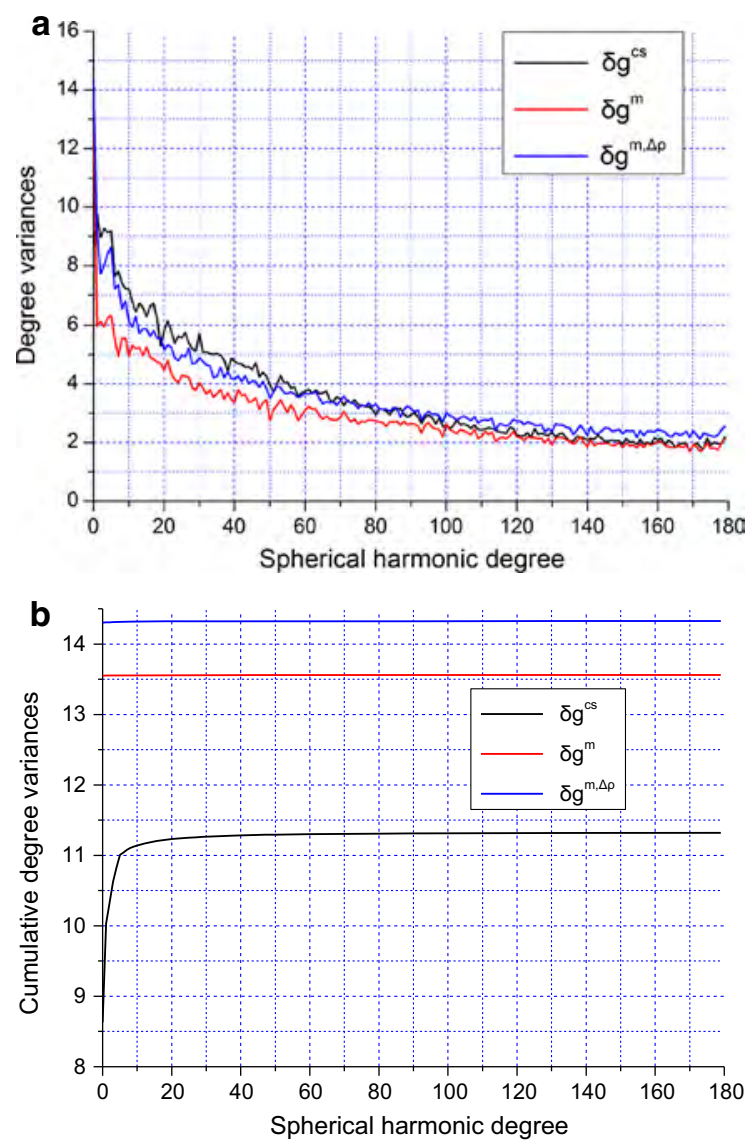

Figure 11

Power spectrum of the consolidated crust-stripped gravity disturbances $\delta g^{\mathrm{cs}}$ and the complete crust-stripped gravity disturbances $\delta g^{m}$ and $\delta g^{m, \Delta \rho}$ for the constant and variable Moho density contrast models, respectively: a the degree variances and $\mathbf{b}$ the cumulative degree variances

the gravitational signature of the Moho geometry. This is evident from the gravity map in Fig. 1. These gravity disturbances are highly spatially correlated with the Moho geometry. Tenzer et al. (2014) demonstrated that this (absolute) correlation is 0.98 . Similarly, a very high correlation was reported by Tenzer et al. (2009b, 2012c). Moreover, the spectral correlation analysis in Fig. 13a revealed that this correlation is particularly pronounced at long-tomedium wavelengths. In a higher-frequency part of the gravity spectrum, this correlation decreases (in the absolute sense), probably because of weakening of the Moho profile and possibly also because of noise in gravity and crustal structure models. The consolidated crust-stripped gravity disturbances also
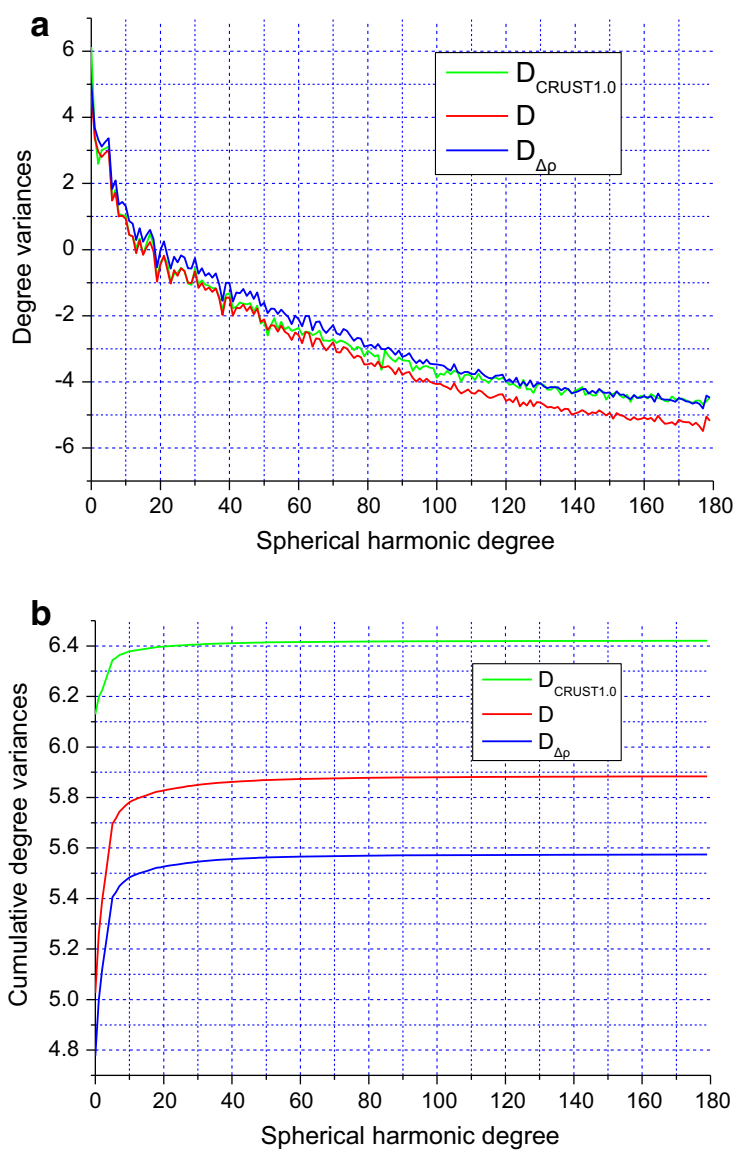

Figure 12

Power spectrum of the Moho geometry ( $D_{\text {CRUST1.0 }}$, the CRUST1.0 Moho depths; $D$, the gravimetric Moho depths for the constant Moho density contrast models; and $D_{\Delta \rho}$, the gravimetric Moho depths for the variable Moho density contrast): a the degree variances and $\mathbf{b}$ the cumulative degree variances

contain the redundant gravitational signal of (unmodeled) mantle heterogeneities, especially at long wavelengths, where we also observe the largest (absolute) correlation of these gravity data with the Moho geometry. A possible explanation is that the Moho geometry is highly correlated with the mantle density structure. To examine this assumption, we plotted the spectral correlation of the CRUST1.0 upper mantle density with the Moho geometry (Fig. 14). It is apparent the profile of the (upper) mantle density structure in the Moho geometry is particularly enhanced at long wavelengths. Moreover, we can see that the mantle density structure is more pronounced in Fig. 5b. Application of the generalized compensation model thus revealed more realistically 

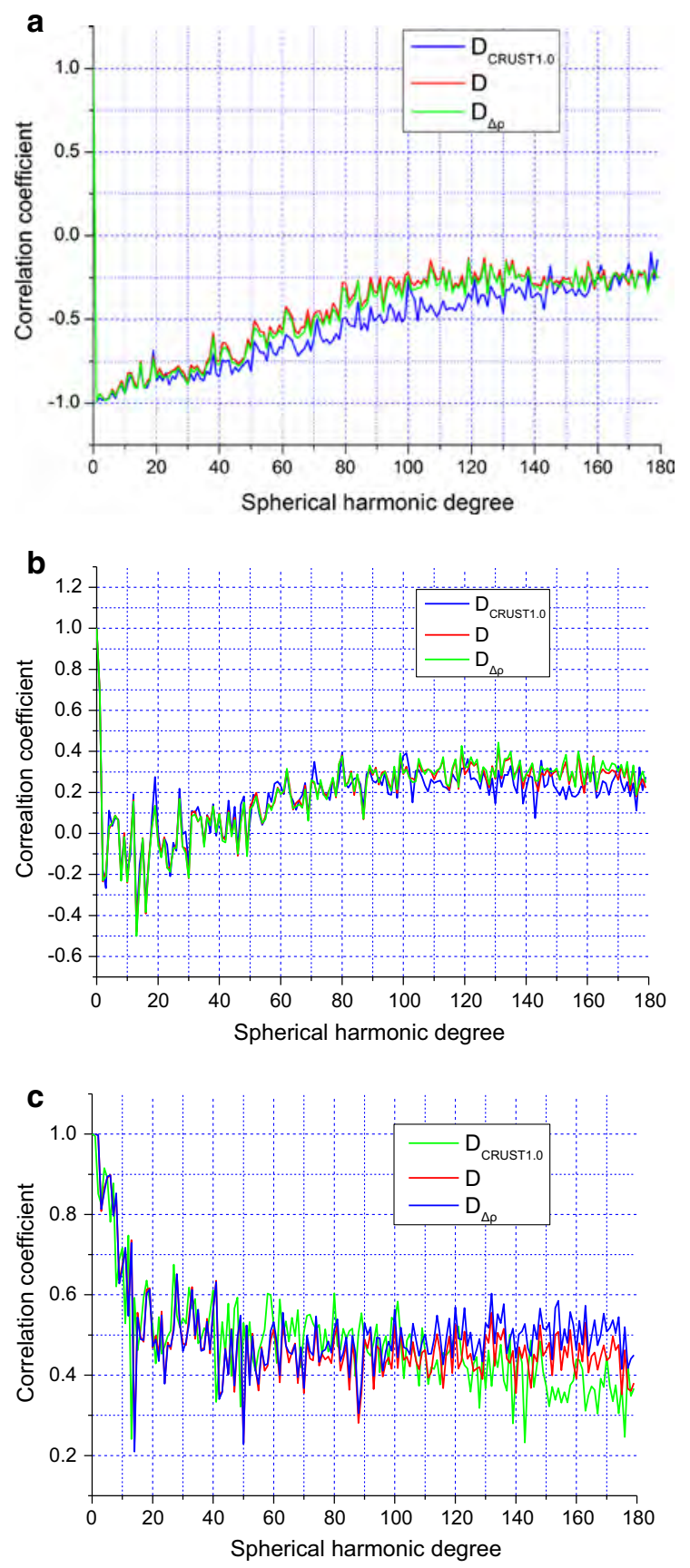

Figure 13

Correlation spectrum of a the consolidated crust-stripped gravity disturbances $\delta g^{\mathrm{cs}}$, b the complete crust-stripped gravity disturbances $\delta g^{m}$ (for the constant Moho density contrast), and $\mathbf{c}$ the complete crust-stripped gravity disturbances $\delta g^{m, \Delta \rho}$ (for the variable Moho density contrast) with the Moho geometry ( $D_{\text {CRUST1.0 }}$, the CRUST1.0 Moho depths; $D$, the gravimetric Moho depths for the constant Moho density contrast; and $D_{\Delta \rho}$, the gravimetric Moho depths for the variable Moho density contrast)

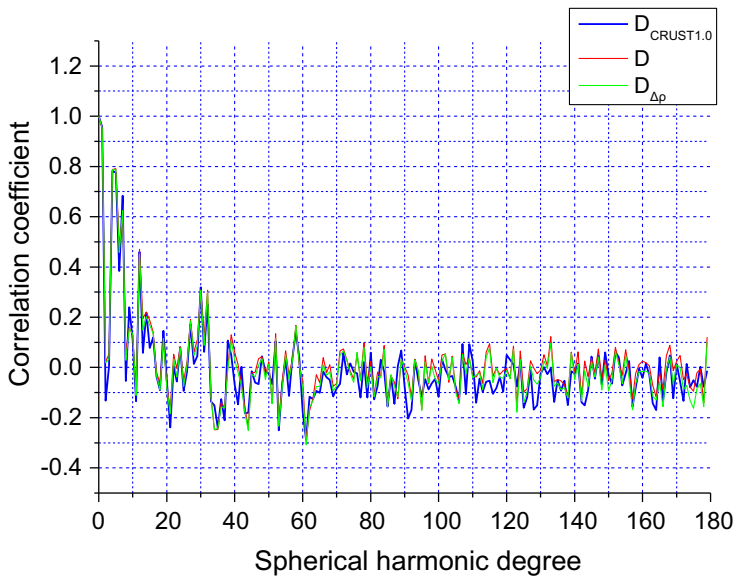

Figure 14

Correlation spectrum of the CRUST1.0 upper mantle density structure (shown in Fig. 3 b) with the Moho geometry ( $D_{\text {CRUST1.0, }}$, the CRUST1.0 Moho depths; $D$, the gravimetric Moho depths for the constant Moho density contrast; and $D_{\Delta \rho}$, the gravimetric Moho depths for the variable Moho density contrast)

the mantle density structure. This is not surprising, because the upper mantle density structure was used to compute the variable Moho density constant (which was adopted in the definition of the generalized compensation scheme). This finding is also confirmed by the results from spectral correlation analysis. Application of the standard compensation model removed almost entirely the Moho signature from the whole spectrum of the complete cruststripped gravity disturbances. As is apparent from Fig. 13b, the correlation between the complete cruststripped gravity disturbances $\delta g^{m}$ and the Moho geometry is almost completely absent. In contrast, the complete crust-stripped gravity disturbances $\delta g^{m, \Delta \rho}$ (obtained after applying the generalized compensation scheme) are highly spatially correlated with the Moho profile in the long-wavelength gravity spectrum (Fig. 13c). This is explained by the fact that the upper mantle structure and the Moho geometry are also highly spatially correlated at the long wavelengths (Fig. 14).

\section{Summary and Concluding Remarks}

We have formulated the gravimetric inverse problem for determination of Moho geometry based 
on adopting the generalized compensation model. This model takes into consideration the variable depth and density of compensation (defined by means of the variable Moho depth and density contrast). The generalized compensation model was compared with the standard compensation model (which assumes only a variable Moho depth). This formulation differs from the generalized VMM model defined by SJÖBERG and BAGHERBANDi (2011). They formulated the VMM inverse problem of isostasy for simultaneous estimation of the Moho depth and density contrast. In our inversion scheme, we estimate the Moho depth only - the variable Moho density contrast is fixed.

The Moho density contrast (defined relative a the reference crustal density of $2,670 \mathrm{~kg} \mathrm{~m}^{-3}$ ) was found to be $445 \mathrm{~kg} \mathrm{~m}^{-3}$. This value agrees very closely with the global average of $448 \pm 187 \mathrm{~kg} \mathrm{~m}^{-3}$ estimated by SJöBERG and BAgherbandi (2011). These two estimates differ by approximately $7 \%$ from the value of $485 \mathrm{~kg} \mathrm{~m}^{-3}$ reported by TENZER et al. (2012c) and the value of $480 \mathrm{~kg} \mathrm{~m}^{-3}$ adopted in the definition of the PREM (DzIEwONSKI and ANDERSON 1981, Table 1).

We used CRUST1.0 data for the upper mantle density to derive the laterally varying model of the Moho density contrast relative to the reference crustal density. This model does not furnish the real density contrast at the Moho interface, because it is not measured relative to the overlying lower crustal density. Such a definition is, however, equivalent to the principle of computing the stripping gravity corrections, in which the density contrasts of crustal structures are again measured relative to the reference crustal density.

Analysis of the CRUST1.0 lower crust and upper mantle density variations showed that the "real" Moho density contrast varies between 10 and $610 \mathrm{~kg} /$ $\mathrm{m}^{-3}$. This density contrast resembles, to some extent, the global tectonic configuration. The density contrast under the oceanic crust is typically less pronounced than under the continental crust. The density contrast minima mark distinctively the divergent tectonic plate boundaries. The density contrast maxima are typically found under the orogens and cratonic shields and platforms.

The variable Moho density contrast in our model (implicitly) incorporated information about the density structure within the upper mantle and consequently its effect on Moho geometry. In the absence of a 3D mantle density model, however, density heterogeneities within the whole mantle could not be directly modeled and corrected for. The input gravity data used for the Moho gravity inversion thus comprised also the redundant gravitational signal of (unmodeled) mantle heterogeneities, which introduced large systematic bias into the gravimetric Moho results. A possible technique for removing this systematic bias was proposed by BAGHERBANDI and SJöBERG (2012). They used the method of EcKHARDT (1983) and Bowin et al. (1986) to estimate the maximum number of long-wavelength spherical harmonic terms which should be removed from the gravity field. The principle of this procedure was based on finding the representative depth of gravity signal attributed to each spherical harmonic degree term. The spherical harmonics which have a depth below a specific limit (chosen, in our case, as the maximum depth of the lithosphere) are then removed from the gravity field. The input gravity data also contain errors because of gravity and crustal model uncertainties. Tenzer et al. (2012b) estimated that the relative errors in these gravity data can reach approximately $10 \%$. Similar relative errors might be expected in the gravimetrically determined Moho depths.

The isostatic mass balance depends on loading and effective elastic thickness, rigidity, rheology of the lithosphere, and viscosity of the asthenosphere (WAtTs 2001). Moreover, the glacial isostatic adjustment, present-day glacial melting, plate motion, mantle convection, and other geodynamic processes contribute to the overall isostatic balance. The gravimetric methods thus (often) cannot model realistically the actual Moho geometry without use of additional constraining information (retrieved mainly from results of seismic surveys). Despite these theoretical deficiencies of gravimetric methods, the accuracy of Moho determination by using gravity data can be improved substantially by incorporating all available information on the Earth's density structure. As we demonstrated in this study, use of the upper mantle density model improved the RMS fit of the gravimetric result to the seismic model by approximately $30 \%$. The most significant 
improvement of the Moho geometry was observed in regions where the globally averaged value cannot accurately approximate the actual Moho density contrast, for instance, under continent-to-continent and ocean-to-continent convergent tectonic plate boundaries (characterized by large variations in density contrast).

\section{REFERENCES}

Artemieva, I., 2007. Dynamic topography of the East European Craton: shedding light upon the lithospheric structure, composition and mantle dynamics " Global Planet. Change 58, 411-434.

Bassin, C., Laske, G., Masters, T.G., 2000. The current limits of resolution for surface wave tomography in North America. EOS Trans AGU, 81, F897.

Bagherbandi, M., SJöBerg, L.E., 2012. Non-isostatic effects on crustal thickness: A study using CRUST2.0 in Fennoscandia. Phys. Earth Planet. Inter. 200-201, 37-44.

BrattenberG, C., Zadro, M., 1999. Iterative 3D gravity inversion with integration of seismologic data. Boll. Geof. Teor. Appl. 40, 3/4, 469-476.

Braitenberg, C., Wienecke, S., Wang, Y., 2006. Basement structures from satellite-derived gravity field: south China Sea ridge. J. Geophys. Res. 111, B05407.

Braitenberg, C., Mariani, P., Reguzzoni, M., Ussami, N., 2010. GOCE observations for detecting unknown tectonic features. In: Proc. of the ESA Living Planet Symposium, 28 June-2, July 2010, Bergen, Norway, ESA SP-686.

Braitenberg, C., EbBing, J., 2009. New insights into the basement structure of the West Siberian basin from forward and inverse modelling of GRACE satellite gravity data. J. Geophys. Res., 114, B06402, 1-15.

Bowin, C., ScheER, E., SMith, W., 1986. Depth estimates from ratio of gravity, geoid and gravity gradient anomalies. Geophysics. 51, 1, 123-136.

CHEN, W., TENZER, R., 2014. Harmonic coefficients of the Earth's Spectral Crustal Model 180 - ESCM180. Earth Sci. Inf. doi:10. 1007/s12145-014-0155-5.

ČADEK, O., MARTineC Z., 1991. Spherical harmonic expansion of the earth's crustal thickness up to degree and order 30. Studia Geophys. Geodaet. 35, 151-165.

Dziewonski, A.M., Anderson, D.L., 1981. Preliminary reference Earth model. Phys. Earth Planet. Int. 25, 297-356.

ECKHARDT, D.H.,1983. The gains of small circular, square and rectangular filters for surface waves on a sphere. Bull. Geod., 57, 394-409.

GeIss, E., 1987. A new compilation of crustal thickness data for the Mediterranean area. Ann. Geophys. 5B, 623-630.

Gelderen van M., Koop R., 1997. The use of degree variances in satellite gradiometry. J. Geod. 71, 337-343.

Gladkikh, V., Tenzer, R., 2012. A mathematical model of the global ocean saltwater density distribution. Pure App. Geophys. 169, 249-257.
GoOdACRE, A.K., 1972. Generalized structure and composition of the deep crust and upper mantle in Canada. J. Geophys. Res. 77, 3146-3160.

Heiskanen, W.A., Vening Meinesz, F.A., 1958. The Earth and its gravity field. McGraw-Hill Book Company, Inc.

Heiskanen, W.A., Moritz, H., 1967. Physical geodesy. Freeman, W.H., New York.

HinZE, W.J., 2003. Bouguer reduction density, why 2.67? Geophysics $68,5,1559-1560$.

Jin, S.G., van Dam, T., Wdowinski, S., 2013. Observing and understanding the Earth system variations from space geodesy. J. Geodyn. 72, 1-10.

JORDI, J., 2007. Constraining velocity and density contrasts across the crust-mantle boundary with receiver function amplitudes. Geophys. J. Int. 171, 286-301.

Kaban, M.K., Schwintzer, P., Artemieva, I.M., Mooney, W.D., 2003. Density of the continental roots: compositional and thermal contributions. Earth Planet. Sci. Lett. 209, 53-69.

Laske, G., Masters, G., Ma, Z., Pasyanos, M.E., 2012. CRUST1.0: An updated global model of Earth's crust. Geophys. Res. Abs., 14, EGU2012-3743-1, EGU General Assembly 2012.

Mariani, P., Braitenberg, C., Ussami, N., 2013. Explaining the thick crust in Parana' basin, Brazil, with satellite GOCE-gravity observations. J. South Amer. Earth Scie., 45, 209-223.

Martinec, Z., 1994. The minimum depth of compensation of topographic masses. Geophys. J. Int. 117, 545-554.

Mayer-Guerr, T., Rieser, D., Höck, E., Brockmann, J.M., Schuh, W.-D., Krasbutter, I., Kusche, J., Maier, A., Krauss, S., Hausleitner, W., Baur, O., Jäggi, A., Meyer, U., Prange, L., Pail, R., Fecher, T., Gruber, T., 2012. The new combined satellite only model GOCO03 s. Presented at GGHS2012, Venice, October.

Moritz, H., 1990. The figure of the Earth. Wichmann, H., Karlsruhe.

MoriTz, H., 2000. Geodetic Reference System 1980. J. Geod. 74, $128-162$.

Niu, F., James, D.E., 2002. Fine structure of the lowermost crust beneath the Kaapvaal craton and its implications for crustal formation and evolution. Earth Planet. Sci. Lett. 200, 121-130.

NovÁK, P., 2010. High resolution constituents of the Earth gravitational field. Surv. Geoph. 31, 1, 1-21.

Peltier, W.R., 2007. Mantle dynamics and the D-double prime layer implications of the post-perovskite phase. In: Hirose, K., Brodholt, J., Lay, T., Yuen, D. (eds.) Post-Perovskite: The last mantle phase transition, 174, AGU Geophys. Monogr., Amer. Geophys. Un., pp. 217-227.

Phillips, R., LAmBeCK, K., 1980. Gravity fields of the terrestrial planets: long-wavelength anomalies and tectonics. Rev. Geophys. Space Phys. 18, 27-76.

SAmPIETRO, D., 2011. GOCE exploitation for Moho modeling and applications. In: Proc. of the $4^{\text {th }}$ International GOCE User Workshop, 31 March-1 April 2011, Munich, Germany.

Sampietro, D., Reguzzoni, M., Braitenberg, C., 2013. The GOCE estimated Moho beneath the Tibetan Plateau and Himalaya. In: International Association of Geodesy Symposia, Earth on the Edge: Science for a Sustainable Planet, Proceedings of the IAG General Assembly, 28 June-2 July 2011, Melbourne, Australia, Rizos, C. and P. Willis (eds.), vol. 139, Springer-Verlag, Berlin. SJöBERG, L.E., 2009. Solving Vening Meinesz-Moritz inverse problem in isostasy. Geophys. J. Int. 179, 3, 1527-1536. 
SJÖBERG, L.E., 2013. On the isotactic gravity anomaly and disturbance and their applications to Vening Meinesz-Moritz gravimetric inverse problem. Geophys. J. Int. 93, 3, 1277-1282.

SJöBerg, L.E., BAGHERBANDI, M., 2011. A Method of Estimating the Moho Density Contrast with a Tentative Application by EGM08 and CRUST2.0. Acta Geophys. 58, 1-24.

Tenzer, R., Hamayun, Vajda, P., 2009a. Global maps of the CRUST2.0 crustal components stripped gravity disturbances. J. Geophys. Res. 114, B, 05408.

Tenzer, R., Hamayun, Vajda, P., 2009b. A global correlation of the step-wise consolidated crust-stripped gravity field quantities with the topography, bathymetry, and the CRUST2.0 Moho boundary. Contr. Geophys. Geod. 39, 2, 133-147.

Tenzer, R., Novák, P., Vajda, P., Gladkikh, V., Hamayun, 2012a. Spectral harmonic analysis and synthesis of Earth's crust gravity field. Comput. Geosc. 16, 1, 193-207.

Tenzer, R., Gladkikh, V., VAJda, P., NovÁK, P., 2012b. Spatial and spectral analysis of refined gravity data for modelling the crustmantle interface and mantle-lithosphere structure. Surv. Geophys. 33, 5, 817-839.

Tenzer, R., Hamayun, Novák, P., Gladkikh, V., Vajda, P., $2012 \mathrm{c}$. Global crust-mantle density contrast estimated from EGM2008, DTM2008, CRUST2.0, and ICE-5G. Pure Appl. Geophys. 169, 9, 1663-1678.

Tenzer, R., Bagherbandi, M., Gladkikh, V., 2012d. Signature of the upper mantle density structure in the refined gravity data. Comput. Geosci. 16, 4, 975-986.

Tenzer, R., Novák, P., Gladkikh, V., 2012e. The bathymetric stripping corrections to gravity field quantities for a depthdependant model of the seawater density. Mar. Geod. 35, $198-220$.
TEnZer, R., BAgherbandi, M., 2013. Reference crust-mantle density contrast beneath Antarctica based on the Vening Meinesz-Moritz isostatic problem and CRUST2.0 seismic model. Earth. Sci. Res. J. 17, 1, 7-12.

Tenzer, R., Bagherbandi, M., Vajda, P., 2013. Global model of the upper mantle lateral density structure based on combining seismic and isostatic models. Geosc. J. 17, 1, 65-73.

Tenzer, R., Chen, W., 2014a. Expressions for the global gravimetric Moho modeling in spectral domain. Pure Appl. Geophys. $171,8,1877-1896$.

TENZER, R., ChEN, W., 2014b. Regional gravity inversion of crustal thickness beneath the Tibetan plateau. Earth Scie. Infor. doi:10. 1007/s12145-014-0146-6.

Tenzer, R., Chen, W, Tsoulis, D., Bagherbandi, M., SJöberg, L.E., NovÁk, P., JIN, S., 2014. Analysis of the refined CRUST1.0 crustal model and its gravity field. Surv. Geophys. doi:10.1007/ s10712-014-9299-6.

Thybo, H., Artemieva, I.M., 2013. Moho and magmatic underplating in continental lithosphere. Tectonoph., 609, 505-619.

Vening Meinesz, F.A., 1931. Une nouvelle méthode pour la réduction isostatique régionale de l'intensité de la pesanteur. Bull. Geod. 29, 33-51.

WatTs, A.B., 2001. Isostasy and flexure of the lithosphere. Cambridge University Press, Cambridge.

Wienecke, S., Braitenberg, C., Götze, H.-J., 2007. A new analytical solution estimating the flexural rigidity in the Central Andes. Geophys. J. Int. 169, 3, 789-794.

YounG, D., 1971. Iterative solutions of large linear systems. New York: Academic Press.

(Received June 23, 2014, revised September 17, 2014, accepted October 15, 2014, Published online November 18, 2014) 